\title{
Modified Vegetable Oil Based Additives as a Future Polymeric Material-Review
}

\author{
Nikesh B. Samarth, Prakash A. Mahanwar \\ Department Polymer and Surface Engineering, Institute of Chemical Technology, Mumbai, India \\ Email: n.b.samarth@gmail.com,pmahanwar@yahoo.com
}

Received 26 August 2014; revised 19 September 2014; accepted 28 October 2014

Copyright (C) 2015 by authors and Scientific Research Publishing Inc.

This work is licensed under the Creative Commons Attribution International License (CC BY). http://creativecommons.org/licenses/by/4.0/

(c) (i) Open Access

\begin{abstract}
Polymeric materials from renewable resources have attracted a lot of attention in recent years. The development and utilization of vegetable oils for polymeric materials are currently in the spotlight of the polymer and chemical industry, as they are the largest renewable platform due to their universal wide availability, ingrained biodegradability, low cost, and excellent environmental aspects (i.e., low ecotoxicity and low toxicity toward humans). These excellent natural characteristics are now being taken advantage of in research and development, with vegetable oil derived polymers/polymeric materials/composites being used in numerous applications including paints and coatings, adhesives, and nanocomposites. The aim of this review paper is to give a fundamental description of the various vegetable oil applications in polymer materials and its recent developments. Particular emphasis will be placed on study and main application of triglyceride based additive for polymer and to give the reader an insight into the main developments is discussed.
\end{abstract}

\section{Keywords}

Vegetable Oil, Additives, Renewable Material, Polymer, Stabilizer, Plasticizer, Lubricant

\section{Introduction}

Vegetables or plant oils represent a renewable resource that can be used as reliable starting material to access new products with a wide array of structural and functional variations. The ample availability and the relatively low cost make plant oils an industrially attractive raw material for the plastics industry.

Already for a long time, plant oils and their derivatives have been used by polymer chemists due to their renewable nature, world wide availability at relatively low price, and their wide application possibilities. In recent year, there has been a large amount of demand for plant oils as an alternative resource for the production of ad- 
ditive for various applications such as polymer, coating, adhesive and nanocomposite [1]-[5]. The necessity of releasing the polymer industry from its dependence on depleting resources represents a major concern, pushing the search for industrially applicable renewable alternatives. In this case, plant oils offer many advantages apart from their renewability. Their worldwide availability and relatively low prices make them industrially attractive and feasible, as daily demonstrated with industrial oleo chemistry. The largest sources of vegetable oils are annual plants such as soybean, corn, linseed, cottonseed or peanuts. However, other sources are oil-bearing perennials such as the palm, olive or coconut [6].

Naturally occurring plant oils and fatty acids derived mostly are considered to be the most important renewable feedstock processed in the chemical industry and in the preparation of bio-based functional polymers and polymeric materials [7]-[10].

The main constituents of plant oils are triglycerides (see Figure 1(A)). 90\% - 95\% of the total weight of triglycerides accounts for fatty acids and their content is characteristic of each plant oil (Figure 1(A)). The structures of some frequently studied fatty acids are depicted in Figure 1(B). Fatty acid percentage composition of common plant oils is given in Table 1 .

Vegetable oils with high viscosity indices, low volatility and a high flash point have been applied in a series of applications as lubricants and additives in polymer, coatings and resins [7]. For example, epoxidized vegetable oil not only improves the stability of the oil, but also provides adequate reactivity to form chemical linkages with other polymer chains. For example, vernonia oil, in conjunction with other epoxidized plant oils, has been used as a plasticizer and stabilizer to modify the properties of plastic resins or to act as a reactive modifier (diluent or toughener) in epoxy resins [11]-[14].

In general, today it is possible for researcher to chemically modify and transform the triglyceride into reactive group via epoxidation, epoxidation \& metathesis of double bond, acrylation of epoxies reaction with maleic anhydride or tran- sesterification. Because of functional epoxies group on the structure of epoxidized vegetable oil and relatively high oxirane content of linseed and soybean oil, presently it is used in appropriate curing agents in order to produce bio-based epoxies system with satisfactory properties [15]. Vegetable oils were commonly used as poly(vinyl chloride) plasticizers, stabilizers, lubricants and starting materials to produce polyols, pre-polymers in surface coating formulations and to synthesize of polyurethane foams [16]-[19]. Also, modified vegetable oils could be used to improve the efficiency of the fabrication process of linoleum floor cloth, to modify other thermoset polymers and to synthesize new polymers that were appropriate for liquid molding [20]-[22].

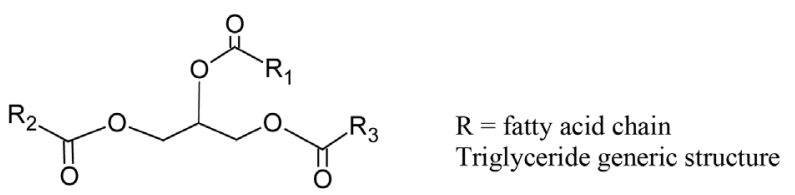

(A)

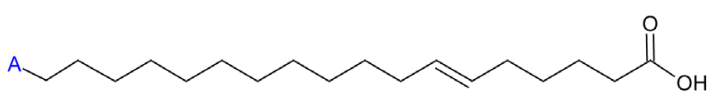

(a)<smiles>[Y]C/C=C/C/C=C/C/C=C/CCCCCCCC(=O)O</smiles>

(c)<smiles>CCCCCCC(O)CC=CCCCCCCC(=O)O</smiles>

(e)<smiles>C=CCCCCCCC(=O)O</smiles>

(g)

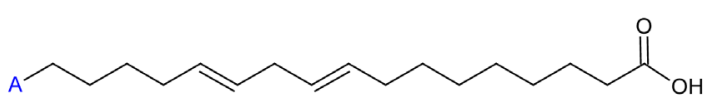

(b)<smiles>CCCCCC/C=C/CCCCCCCCCCC(=O)O</smiles>

(d)<smiles>O=C(O)CCCCCC/C=C/CC1OC1CCCCC[Tl]</smiles>

(f)

(B)

Figure 1. (A) General triglyceride structure; (B) Fatty acids commonly used in polymer chemistry: (a) oleic acid; (b) linoleic acid; (c) linolenic acid; (d) erucic acid; (e) ricinoleic acid; (f) vernolic acid; (g) 10-undecenoic acid. 
Table 1. Fatty acid percentage composition of common plant oils (x:y stands for chain carbon atoms: number of unsaturation) [6].

\begin{tabular}{ccccccccccccc}
\hline & $14: 0$ & $14: 1$ & $16: 0$ & $16: 1$ & $17: 0$ & $17: 1$ & $\mathbf{1 8 : 0}$ & $\mathbf{1 8 : 1}$ & $\mathbf{1 8 : 2}$ & $\mathbf{1 8 : 3}$ & $\mathbf{2 0 : 0}$ & $\mathbf{2 0 : 1}$ \\
\hline Canola & 0.1 & 0.0 & 4.1 & 0.3 & 0.1 & 0.0 & 1.8 & 60.9 & 21.0 & 8.8 & 0.7 & 1.0 \\
Corn & 0.1 & 0.0 & 10.9 & 0.2 & 0.1 & 0.0 & 2.0 & 25.4 & 59.6 & 1.2 & 0.4 & 0.0 \\
Linseed & 0.0 & 0.0 & 5.5 & 0.0 & 0.0 & 0.0 & 3.5 & 19.1 & 15.3 & 56.6 & 0.0 & 0.0 \\
Olive & 0.0 & 0.0 & 13.7 & 1.2 & 0.0 & 0.0 & 2.5 & 71.1 & 10.0 & 0.6 & 0.9 & 0.0 \\
Palm & 1.0 & 0.0 & 44.4 & 0.2 & 0.1 & 0.0 & 4.1 & 39.3 & 10.0 & 0.4 & 0.3 & 0.0 \\
Soybean & 0.1 & 0.0 & 11.0 & 0.1 & 0.0 & 0.0 & 4.0 & 23.4 & 53.2 & 7.8 & 0.3 & 0.0 \\
Sunflower & 0.0 & 0.0 & 6.1 & 0.0 & 0.0 & 0.0 & 3.9 & 42.6 & 46.4 & 1.0 & 0.0 & 0.0 \\
High oleic & 0.0 & 0.0 & 6.4 & 0.1 & 0.0 & 0.0 & 3.1 & 82.6 & 2.3 & 3.7 & 0.2 & 0.4 \\
\hline
\end{tabular}

In addition, the largest proportion of vegetable oils, approximately $80 \%$, was utilized for food, while the share was taken up by the industrial sectors. Triglyceride oils have been utilized quite extensively to produce coatings, inks, plasticizer and lubricants. Within the polymer field, the application of these oils as toughening agents was also reported. Barrett et al. worked to produce vegetable oil based interpenetrating polymer network (IPN) [23]. Also Querishi and his co-workers developed an IPN consisting of cross-linked polystyrene and an epoxidized linseed oil elastomer [24].

Figure 2 shows the life cycle of polymers based on vegetable oils, according to which the biomass from plant-derived resources is extracted in order to yield the vegetable oil. Subsequently, the oil is submitted to chemical modification with the aim of enhancing its reactivity towards a given type of polymerization approach. The polymers are then made available to the consumers, and once used, they become waste, which after degradation and assimilation is reused as biomass and the cycle starts again.

Acrylated soybean oil has been used extensively in the area of surface coatings and is commercially manufactured in forms such as EBECRYL 860 (UCB Chemical Company). Epoxidized soybean oil and epoxidized linseed oil are predominantly used as an alternative plasticizer and stabilizer in PVC in place of phthalates.

The world production of major oilseeds has increased in the last ten years from 331 to 457 million tonnes. According to the United States Department of Agriculture, soybean oilseeds represent over half of the total production of oilseeds and are mainly grown in Brazil, USA and Argentina, followed by rapeseed (grown in EU-27, Canada and China), cottonseed (China and India) and sunflower oilseeds (Ukraine, EU-27 and Russia) [25]. Accordingly, the world production of major vegetable oils has risen from 95 million tonnes in 2002/2003 to 154 million tonnes in 2012/2013 at an average rate just over 5 million tonnes a year [25] as depicted in Table 2. Although the majority of vegetable oils are primarily produced for food and feed purposes, minor vegetable oils like castor and linseed oil are almost solely used for industrial applications [26] [27].

The palm and soybean oil are the most widespread oils, with an annual production of some 52 and 24 million tonnes, respectively, followed by rapeseed and sunflower seed oil, with about 23 and 13 million tonnes, respectively. Exports at 64 million tonnes are even more dominated by palm and soybean oil with 40 and 8.5 million tonnes, respectively [25].

Research on development of vegetable oil based polymeric materials, including additives, biocomposites and nanocomposites, has attracted increasing attention in recent years. In this review, our motivation is to provide a perspective on how vegetable oil based materials are used as an additive for polymer in a great number of applications like polymeric additive, coating and composite application.

\section{Various Widely Used Triglycerides for as an Additive for Polymer}

Vegetable oils, from edible-non edible oil to drying oils, are a big source of polymeric material precursors that can be modified to exhibit various types of functionalities. Large number of Research paper has already been published reflecting the international efforts to use these natural products to produce novel polymers and polymer precursors for increasing the number of its potential applications. Triglyceride molecules can be chemically 
Table 2. Major vegetable oils: World production, trade and consumption (million tonnes) [10].

\begin{tabular}{ccccc}
\hline \multirow{2}{*}{ Oils } & $\mathbf{2 0 0 2 / 2 0 0 3}$ & \multicolumn{3}{c}{$\mathbf{2 0 1 2 / 2 0 1 3}$} \\
\cline { 2 - 5 } & Production & Production & Exports & Consumption \\
\hline Coconut & 3.16 & 3.52 & 1.70 & 3.75 \\
cottonseed & 3.51 & 5.16 & 0.12 & 5.19 \\
Olive & 2.51 & 2.94 & 0.77 & 3.05 \\
Palm & 27.71 & 52.33 & 40.36 & 51.69 \\
Soybean & 30.57 & 42.69 & 8.50 & 43.57 \\
Sunflower & 8.12 & 13.13 & 5.80 & 13.24 \\
Rapeseed & 12.21 & 23.21 & 3.62 & 23.62 \\
\hline
\end{tabular}

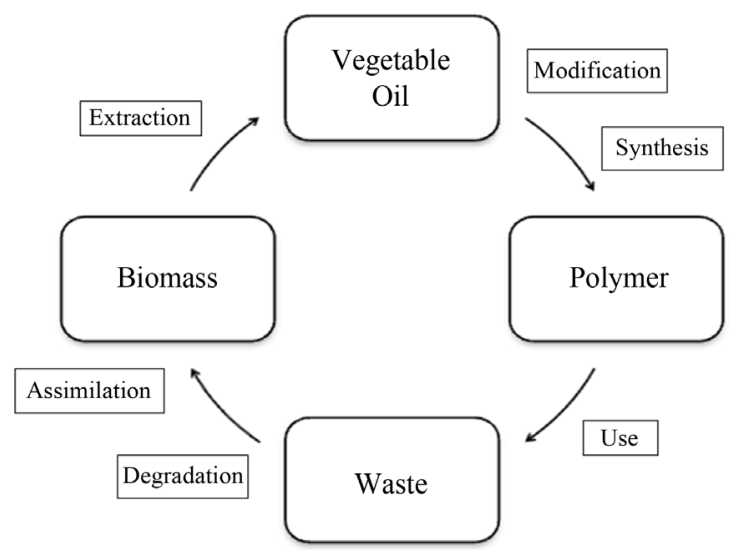

Figure 2. Life cycle of polymeric material based on vegetable oils [11].

modified through hydrolysis or transesterification or by reacting/modifying unsaturations present in the fatty acid chains. This last option leads to a large variety of functionalized molecules, with those containing epoxy or hydroxyl groups being probably the most popular choice. The interested reader may access exhaustive reviews on the chemical modification of vegetable oils for the production of polymeric materials [1]-[5].

Vegetable oils are triglycerides basically extracted from plants. Such oils have been part of human culture for millennia. Edible vegetable oils are used in food, both in cooking and as supplements. Many oils, edible and otherwise, are burned as fuel, such as in oil lamps and as a substitute for petroleum-based fuels. Some of the many other uses include wood finishing, oil painting, and skin care.

The main constituents of plant oils are triglycerides which are the product of esterification of glycerol with three fatty acids. Fatty acids account for $95 \%$ of the total weight of triglycerides and their content is characteristic of each plant. These triglycerides contain several reactive sites, such as double bonds and ester groups, opening up various possibilities to tailor and develop new structures. The term "vegetable oil" can be narrowly defined as referring only to substances that are liquid at room temperature, or broadly defined without regard to a substance's state of matter at a given temperature. For this reason, some of the entries on this list do not qualify as vegetable oils according to all understandings of the term.

Although most plants contain some oil, only the oil from certain major oil crops complemented by a few dozen minor oil crops is widely used and traded. These oils are one of several types of plant oils.

Vegetable oils can be classified in several ways, for example:

- By source: most, but not all vegetable oils are extracted from the fruits or seeds of plants, and the oils may be classified by grouping oils from similar plants, such as "nut oils".

- By use: as described above, oils from plants are used in cooking, for fuel, for cosmetics, for medical purposes, and for other industrial purposes.

The vegetable oils are grouped below in common classes of use. Types of edible oil include olive oil, palm oil, 
soybean oil, canola oil (rapeseed oil), pumpkin seed oil, corn oil, sunflower oil, safflower oil, peanut oil, grape seed oil, sesame oil, argan oil, rice bran oil and other vegetable oils, as well as animal-based oils like butter and lard.

The annual global production of the major vegetable oils (from palm trees, soybeans, rapeseeds, cotton, sunflower, palm kernel, olives, and coconuts) amounted to 84.6 million tons (Mt) in 1999/2000 and increased to 137.3 Mt in 2009/2010 (an increase of 62\%). The production of fatty acids is the highest volume oleochemical process and accounts for about $52 \%$ of industrially used oils and fats. The world supply of fatty acids has almost doubled from 2001 to 2008 [28].

The composition of the fatty acids contained in the oil (fatty acid spectrum) determines the further use of the oils. Special attention must be given to coconut oil and palm kernel oil (lauric oils) because of their high share of fatty acids with a short or medium chain length (mainly 12 and 14 carbon atoms: C12, C14). For example, these are particularly suitable for further processing to surfactants for washing and cleansing agents as well as cosmetics. Palm, soybean, rapeseed, and sunflower oil, as well as animal fats such as tallow, contain mainly longchain fatty acids (e.g., C18, saturated and unsaturated) and are used as raw materials for polymer applications and lubricants (Figure 1) [3]-[5].

The past century has witnessed polymers progress from a laboratory curiosity to large volume applications. The development and use of a wide variety of additives contributed to this. The use of relatively small quantity of this additive improves the processability of the polymer as well as the performance of the end product. The demand for plastic products increases constantly.

There are several applications of oleo chemicals in plastics. Typical applications for fatty esters are:

Lubricants (both internal and external) reduce friction in process equipments, Antistatic agents avoid the building up of electric charges, Antifogging agents prevent formation of water droplets in film applications, Plasticizers change the "brittleness" of a polymer and Stabilizer to improve the thermal stability of polymer.

By changing the following characteristics a wide variety of specifications of the end product can be attained:

- Alcohol type (monoalcohol, polyol): e.g., butanol, ethylhexanol, pentaerythritol, etc.;

- Fatty acid: e.g., oleic acid, stearic acid etc.;

- Chain length;

- Saturation;

- Degree of esterification.

Oleochemistry is a tailor-made chemistry; demands of the customer can be translated into an ester that yields the required performance.

\section{Chemical and Physical Characteristics of Various Vegetable Oil}

The two most immediately useful parameters for assessing the purity of vegetable oils are Saponification values and iodine value (Shashidhara, 2010) [29]. Some typical values are listed in Table 3.

\section{Modification of Vegetable Oil}

Chemically modified plant oils have been used as additives in inks and coatings [36], as toughening agents in poly (vinyl chloride) and epoxy resins [37], as the major components of a number of natural resins [5], composites [38], and pressure-sensitive adhesives [39].

Triglyceride molecules are formed by three fatty acid chains joined to glycerol by ester groups. The fatty acids involved contain a varied number of carbon-carbon double bonds, but unless these double bonds are conjugated, they are not reactive enough to produce viable materials by free radical or cationic polymerization. For that reason, the isomerization of different plant oils containing non conjugated multiple unsaturations has been reported as a first step for carrying out crosslinking by cationic polymerization, for example conjugated linseed oil and low saturation soybean oil have been prepared using a rhodium-based catalysts [40]. On the other hand, the naturally conjugated triene structure of the tung oil makes it well fitted to polymerize by cationic polymerization [41] [42] without any previous modification [43]. On the other hand, the modification of the double bonds can incorporate functionalities like maleates, hydroxyl [44] [45] or epoxy [46] [47] groups making possible a further reaction via ring opening or polycondensation polymerization. After this reaction step, the product can be used without further modification in crosslinking reactions or it can be further modified through other chemical steps broadening the variety of functional molecules to be obtained. For example, the epoxidized triglycerides 
Table 3. Physico-chemical properties of vegetable oils.

\begin{tabular}{|c|c|c|c|c|c|c|c|c|}
\hline \multirow[b]{2}{*}{ Properties } & $\begin{array}{c}\text { Soybean } \\
{[11]}\end{array}$ & $\begin{array}{c}\text { Sunflower } \\
{[30]}\end{array}$ & $\begin{array}{c}\text { Rapeseed } \\
{[31]}\end{array}$ & $\begin{array}{c}\text { Jojoba } \\
{[32]}\end{array}$ & $\begin{array}{c}\text { Jatropha } \\
{[31][33]}\end{array}$ & $\begin{array}{c}\text { Neem } \\
{[34]}\end{array}$ & $\begin{array}{c}\text { Castor } \\
{[31][35]}\end{array}$ & Linseed oil \\
\hline & & & & & & & & \\
\hline $\begin{array}{l}\text { Kinematic Viscosity } \\
\text { @ } 40^{\circ} \mathrm{C}(\mathrm{cSt})\end{array}$ & 32.93 & 40.05 & 45.60 & 24.90 & 47.48 & 68.03 & 230.6 & 33.1 \\
\hline $\begin{array}{l}\text { Kinematic Viscosity } \\
\text { @ } 100^{\circ} \mathrm{C}(\mathrm{cSt})\end{array}$ & 08.08 & 9.02 & 8.65 & 06.43 & 08.04 & 10.14 & 19.72 & - \\
\hline Viscosity Index & 219 & - & 206 & 233 & 208 & 135 & 220 & - \\
\hline $\begin{array}{l}\text { Saponofication Value } \\
\left(\mathrm{mg} \cdot \mathrm{KOH} \cdot \mathrm{g}^{-1}\right)\end{array}$ & 189 & - & - & 94.69 & 196.80 & 166 & 180 & 190 \\
\hline Acid value $\left(\mathrm{mg} \cdot \mathrm{KOH} \cdot \mathrm{g}^{-1}\right)$ & 0.61 & 0.12 & - & 1.10 & 3.20 & 23.00 & 1.40 & 0.80 \\
\hline Iodine value ( $\mathrm{mg} \mathrm{I}_{2} / \mathrm{g}$ Oil) & 144 & 85 & - & 98.0 & 97 & 66.0 & 87 & 177 \\
\hline Flash point $\left({ }^{\circ} \mathrm{C}\right)$ & 240 & - & 252 & - & 240 & - & 250 & - \\
\hline
\end{tabular}

can be reacted to attach vinyl functionalities. Acrylates have been incorporated by reaction of the epoxy groups with acrylic acid, and as an example the acrylated epoxidized soybean oil (AESO) has been frequently reported in the preparation of bio-based polymers and composites [48]. On the other hand, maleate half esters and esters can be prepared by the reaction of hydroxylated triglycerides with maleic anhydride. Further on, these monomers can be blended with reactive diluents and cured by free radical polymerization to obtain thermoset polymers [49]. The stability of vegetable oils could be improved by chemical modification methods [50].

Various kinds of modification to manufacture lubricant base fluids are [50]:

Modifications of the carboxyl group

- Esterification/transesterification.

Modifications of the fatty acid chain

- Selective hydrogenation [51], Dimerization/oligomerisation, Formation of C-C and C-O bonds, Metathesis, Oxidation [52] [53].

The chemical functionalization of vegetable oils can therefore be performed either at 1) the ester groups of triglycerides or 2) at any reactive functionality along the aliphatic chain of the fatty acids [54], as exemplified in Figure 3.

\section{Application of Modified Vegetable Oil Based Additive in Polymer}

\subsection{Stabilizers}

The first experimental documentation on the chemistry of the stabilization of PVC by metallic soaps was reported by Frye and Horst (1959) [55]. The major function of the stabilizers which have given satisfactory commercial service has been to react with the hydrogen chloride split off from PVC on thermal processing ((Anderson and Mckenzie (1970)) [49]. Epoxidized vegetable oil compounds are well known as typical non-metallic stabilizers for PVC. The primary stabilization effect of epoxy plasticizers is that it acts as acceptors for the liberated hydrogen chloride. The importance of these epoxy compounds is due to their co-stabilizing effect in combination with almost all stabilizer system, but especially in combination with metal carboxylate stabilizers. Furthermore, these substances also have a lubricating section. Anderson and McKenzie (1970) have investigated the combined effect of an epoxy compound and metal carboxylates in model reaction. The stabilizing effect of epoxidized sunflower oil (ESO) on the thermal degradation of PVC in presence and absence of different metal carboxylates combinations $(\mathrm{Ca} / \mathrm{Zn}$ and $\mathrm{Ba} / \mathrm{Cd}$ stearates) has been investigated by M.T. Benaniba and other [56]. Also the Performances of ESO were compared to those of epoxidized soya bean oil (ESBO) in the same conditions and it has been found that stabilizing performances of ESO are better than those of ESBO. The effect of 


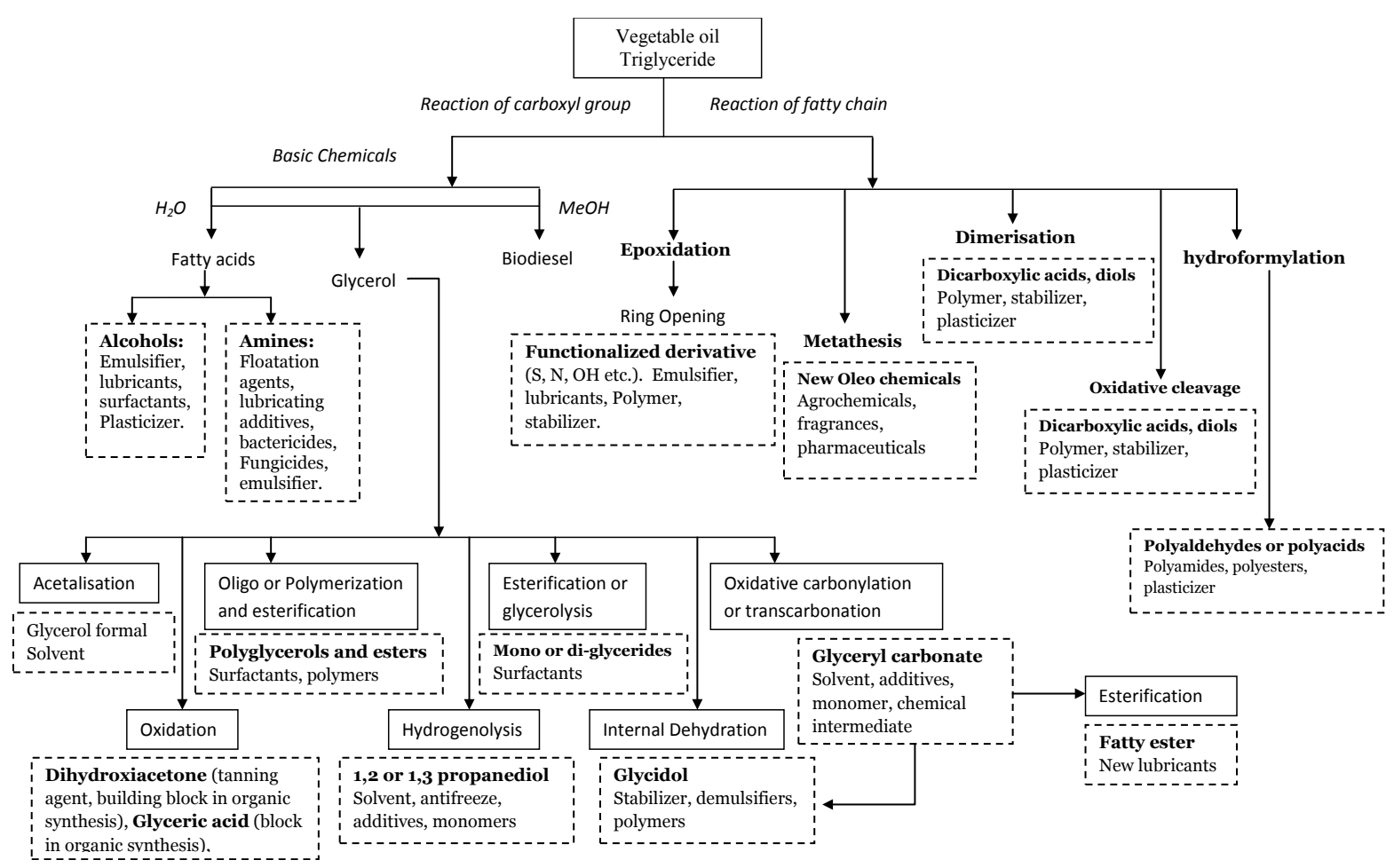

Figure 3. Routes for the preparation of valuable products from fats and oils [27].

ternary stabilizer system (Epoxidized sunflower oil (ESO), Zn and Ca stearates) on the stabilization of PVC shows that the ternary system retards the development of discoloration and reduces the initial rate of dehydrochlorination [57].

Lerke et al. [58] investigated effects of gamma irradiation on pure PVC and PVC stabilized with epoxidized soybean oil, and found that the concentration of conjugated polyene sequences of PVC stabilized with epoxidized soybean oil was lower. Housell [59] investigated the coloration of PVC exposed to gamma radiation. When PVC mixtures containing 5 and $10 \mathrm{phr}$ ESO were exposed to gamma radiation, it seemed that coloration had been decreased compared to control samples. Troitskii et al. [60] observed that the addition of polyols to PVC mixtures containing $\mathrm{ZnSt}_{2}$ and epoxy created a synergetic effect. The synergistic effect of $\mathrm{ZnSt} 2$ and ESO on thermal stability of rigid and plasticized PVC processed with conventional methods such as solvent casting or extrusion was also reported [61] [62]. Not only the ESO or ESBO but the effect of ERSO as a stabilizer also reported and epoxidized rubber seed oil (ERSO) has been shown to retard the dehydrochlorination of PVC using rate measurements obtained from a degradation tube [63]-[65].

The effect ESO also studied by Badra et al. (2008) a novel plasticizer of poly(vinyl chloride) (PVC) resins, epoxidized sunflower oil (ESO), was synthesized, and its performance was evaluated. ESO was designed to act as a coplasticizer and a heat stabilizer like ESBO. ESO is used as organic coplasticizer for plasticized PVC containing $\mathrm{Ca}$ and $\mathrm{Zn}$ stearates as primary stabilizers and stearic acid as lubricant [66]. Commercial sunflower oil was epoxidized and the stabilizing effect of epoxidized sunflower oil (ESO) was reported in combination with the different metal and other heat stabilizer foe example [67].

\subsection{Lubricant}

Vegetable oil as a lubricant is preferred not only because they are renewable raw materials but also because they are biodegradable and non-toxic (Randles and Wright, 1992; Battersby et al., 1998) [28] [68]-[70]. They also acquire most of the properties required for lubricants such as high index viscosity, low volatility and good lubricity and are also good solvents for fluid additives. However, vegetable oils have poor oxidative and thermal stability, which is due to the presence of unsaturation [71]. This unsaturation restricts their use as a good lubricant. Several attempts have been made to improve their oxidative stability such as transesterification of trime- 
thylopropane and rapeseed oil methyl ester [72]; selective hydrogenation of polyunsaturated $\mathrm{C}=\mathrm{C}$ bonds of fatty acid chains [73] and conversion of $\mathrm{C}=\mathrm{C}$ bonds to oxirane ring via epoxidation [74] [75]. Among these, epoxidation received special attraction because it opened up a wide range of feasible reactions that can be carried out under moderate reaction conditions due to the high reactivity and functionality of the oxirane ring [76]. For instance, the epoxides can react with different nucleophiles to produce mono-alcohols, diols, alkoxyalcohols, hydroxyesters, N-hydroxyalkylamides, mercaptoalcohols, aminoalcohols, hydroxynitriles, etc. [77].

Adhvaryu and Erhan reported epoxidized soybean oil as a potential source for high temperature lubricants applications [11]. Gast et al. reported that the product obtained by ring-opening reaction of epoxidized fatty acid esters followed by esterification of the resulting hydroxyl group shows good performance for lower temperature lubricant applications [70]. Lathi and Mattiasson (2007) reported a novel process for the production of biodegradable lubricant-based stocks from epoxidized vegetable oil with a lower pour point via cationic ion-exchange resins as catalysts. This involves two steps, first, ring-opening reactions by alcoholysis followed by esterification of the resultant hydroxy group in the first step [78].

The triglyceride structure of vegetable oils provides qualities desirable in a lubricant. Long, polar fatty acid chains provide high strength lubricant films. The strong intermolecular interactions are also resilient to changes in temperature providing a more stable viscosity, or high viscosity coefficient. The entire base oil is also a potential source of fatty acids. The triglyceride structure is also the basis for the inherent disabilities of vegetable oils as lubricants. Unsaturated double bonds in the fatty acids are active sites for many reactions, including oxidation, lowering the oxidation stability of vegetable oils. Another concern is the susceptibility of the triglyceride ester to hydrolysis. The similarities in all vegetable oil structures mean that only a narrow range of viscosities are available for their potential use as lubricants. Finally, the strong intermolecular interactions whilst providing a durable lubricant film also result in poor low-temperature properties [79].

Campanella et al. (2010) studied two new synthetic routes to polyol-derived intermediates, proposed as an alternative way for the production of lubricants from vegetable oils obtained from temperate climate crops (soybean and sunflower seeds). The oils are first epoxidized, and then the oxirane ring is opened with either acetic acid or a low chain aliphatic alcohol (methanol or ethanol). These routes are promising in that they demand short reaction times and low reaction temperatures, while $99 \%$ conversion is achieved, with high selectivities. Considering only the viscosity of the products, they are all viable lubricant basestocks in which the intermediates can be further esterified to obtain low-temperature lubricants [80].

Wu et al. (2000) reported the application of epoxidized rapeseed oil as a biodegradable lubricant. The epoxidation treatment has no adverse effect on the biodegradability of the base stock. Epoxidized rapeseed oil has superior oxidative stability compared to rapeseed oil based on the results of both oven tests and rotary oxygen bomb tests. The epoxidized rapeseed oil has better friction-reducing and extreme pressure abilities according to tribological investigations. Formation of a tribopolymerization film is proposed as explanation of the tribological performance of epoxidized rapeseed oil [81].

Although many valuable polymeric materials derived from ESO have been reported, preparation of lubricants from the ESO was not found. Gast et al. [77] prepared products with pour points ranging from $-32^{\circ} \mathrm{C}$ to $-51^{\circ} \mathrm{C}$ by a ring-opening reaction of epoxidized fatty acid esters followed by esterification of the resulting hydroxy groups. Herein, author reported the preparation of lubricant candidates from ESO and their pour points and oxidative stabilities. The fluids were prepared from ESO by an acid-catalyzed ring-opening reaction using an alcohol followed by esterification with an acid anhydride. Correlation between pour points and structural variation in the molecules was studied [82]. The development of soybean oil-based lubricants, the preparation of synthetic lubricant base stocks from epoxidized soybean oil and Guerbet alcohols was also reported. The pour point, viscosity, viscosity index, and oxidative stability in micr ooxidation test were evaluated to investigate the effect of structural variation in the oil molecules [83].

\subsection{Plasticizer}

During the last decade, the worldwide production of plasticizers was around 5 million tons per year. These were applied to around 60 polymers and more than 30 groups of products [84]. The use of plasticizers for plastic products manufacture is well known. Its application to modify polymer characteristics began in the 1800s. In these early days, manufacturers of celluloid or celluloid lacquers used natural camphor and castor oil for plasticization purposes, but these were unsatisfactory for many end uses. Later, in 1912, triphenyl phosphate was 
tested to substitute camphor oil, representing the beginning of the ester plasticizers era. Phthalic acid esters found applications as plasticizers for the first time in 1920 and continue to be the largest class of plasticizers in the 21st century [85]. Di(2-ethylhexyl) phthalate (DEHP), also known as dioctyl phthalate (DOP), was introduced in 1930 and has been the most widely used plasticizer since the 1930s. The great variety of plastic products and its numerous applications have led to the development of new and improved plasticizers in order to meet product quality and specification requirements. Over the last half century, legislation and health safety issues have led to the development of a wide range of currently-available commercial plasticizers. They include some fatty acid esters, benzoates, tartrates and chlorinated hydrocarbons, esters of adipic, azelaic and sebacic acid.

Nowadays, there is increasing interest in the use of natural-based plasticizers that are characterized by low toxicity and low migration. This group includes epoxidized triglyceride vegetable oils from soybean oil, linseed oil, castor-oil, sunflower oil, and fatty acid esters (FAEs) [86].

In 1951, the International Union of Pure and Applied Chemistry (IUPAC) developed a universally accepted definition of a plasticizer as a substance or a material incorporated in a material (usually a plastic or an elastomer) to increase its flexibility, workability, or extensibility [87]. Among plasticizers, esters of phthalic anhydride, named phthalates, are the most used, sharing $80 \%$ of the plasticizer market. However, in the last 15 years phthalates have been criticized because of their potential toxicity which includes asthma, neurotoxicity, endocrine problems and cancer [88]. The use of natural and/or biodegradable plasticizers, with low toxicity and good compatibility with several plastics, resins, rubber and elastomers in substitution of conventional plasticizers, such as phthalates and other synthetic conventional plasticizers attracted the market along with the increasing worldwide trend towards use of biopolymers [89].

Suarez Palacios et al. (2013) [90] here the operating conditions of the TisoV (glycerol tri-isovalerate) as a phthalate-free plasticizer are evaluated as part of a methodology for product design starting with molecular considerations, passing to the process design and ending in the acceptability of the product.

Epoxidized soybean oil (ESO) as a plastic additive has a relatively stable market of approximately 100,000 tonnes/year [91]. Epoxides oil function as both plasticizers and stabilizers in polyvinyl chloride (PVC) and other halogenated resins. The high molecular weight and structure make these epoxides compatible in the various resign systems and provide flexibility to the otherwise rigid plastics. These epoxides function as secondary plasticizers when used in conjunction with phthalate based PVC plasticizers systems. Importantly these natural based epoxides can be modified to function as primary plasticizers replacing phthalates. The stabilizer properties of Epoxol epoxides are derived mainly from their acid scavenging properties. Boussoum et al. (2006) studied the specific migration of additives from rigid and plasticised PVC stabilised with ESO in the presence of $\mathrm{Zn}$ and $\mathrm{Ca}$ stearates by using various analytical methods such as the rate of the mass variation, the peroxide index determination, atomic absorption spectrometry and FTIR spectroscopy. FTIR investigation in PVC films after various times of contact with food simulants allowed a semi-quantitative estimation of the migration of ESO, Zn stearate and $\mathrm{Ca}$ stearate. All the results obtained with the various analytical methods used showed that the migration of some additives present in the PVC formulation occurred in the food stimulants [92]. Karmalm (2009) describes what happens to the material when ESBO is used as primary plasticizer in plastisol- and in suspension PVC without any additional stabilizer. When $50 \mathrm{ph}$ ESBO was added to $100 \mathrm{ph}$ plastisol PVC and then aged in a oven at $180^{\circ} \mathrm{C}$ for various lengths of time, the E-modulus increased with ageing time due the formation of a cross linked network induced by a polymerization reaction of the epoxy groups in the ESBO. The network and the PVC were analyzed by NMR which showed that reaction between PVC and ESBO had occurred, and that the network consisted primarily of ESBO. The same experiment performed with suspension PVC instead of plastisol PVC did not result in any crosslinking of the ESBO. The ring opening of the epoxy which starts the polymerization of ESBO is most likely catalyzed by an additive used in the polymerization of plastisol PVC [93].

Emanuela Calo et al. (2011) studied the soft PVC was obtained by using a new plasticizer, based on cardanol, a renewable resource characterized by chemical and physical properties very close to those of diethylhexyl phthalate (DEHP). Cardanol acetate (CA) was obtained by solvent free esterification of cardanol, and used as secondary plasticizer, by partial substitution of DEHP in soft PVC formulations. Ageing tests were performed in order to study the stability of properties of the soft PVC formulations related to plasticizer diffusion. Tensile properties and hardness changes were used to monitor the macroscopic effects of plasticizer diffusion. Soft PVC obtained by partial substitution of DEHP by CA showed a significant modification of mechanical properties related to higher plasticizer evaporation during ageing tests. Migration tests confirmed that CA is characterized by 
a higher diffusivity in soft PVC compared to DEHP. da Silva et al. (2011) reported that, a natural plasticizer was synthesized in the laboratory by esterification of rice fatty acids and polyols. The resulting product was added to PVC and natural rubber latex films $(5 \% \mathrm{w} / \mathrm{w})$. Mechanical tests indicated that the addition of the natural plasticizer resulted in an increase in the elongation at break and a consequent decrease in the tensile strength of the films. The plasticizing effect induced by the natural plasticizer was also confirmed by a glass transition temperature ( $\mathrm{Tg}$ ) shift towards lower temperatures in the plasticized films [94]. Also the preliminary analysis of the applicability of cardanol derivatives as renewable plasticizers for soft PVC was reported. Two different plasticizers were studied, obtained by esterification of the cardanol hydroxyl group (cardanol acetate) and further epoxidation of the side chain double bonds (epoxidated cardanol acetate) [95].

PVC traditional plasticizers based in phthalate have been substituted by epoxidized linseed oil (ELO). From the industrial point of view, this substitution presents an interesting alternative because ELO is a natural product, harmless, and biodegradable. The effects on the Characteristics of plasticized PVC in the migration phenomenon have been analyzed [96]. Recently epoxidized palm oil (EPO) was utilized as a plasticizer for polylactic acid (PLA) using chloroform as a solvent by solution casting process at six weight ratios of PLA/EPO, 95/05, 90/10, $80 / 20,70 / 30,60 / 40$, and 50/50, respectively. The FTIR spectra indicate that there are some molecular interactions by intra molecular hydrogen bond between PLA and EPO. All sets of PLA/EPO blends show high thermal stability and significant improvement of mechanical properties compare to pure PLA. The highest elongation at break (about 210\%) was obtained when the ratio of PLA/EPO blend was 80/20. Morphological results of PLA/ EPO blends show that ESO was good miscible with PLA [97].

\subsection{Composite}

Composites based on environmentally degradable, eco-compatible synthetic and natural polymeric materials have great potential as advanced environmentally acceptable alternatives to petroleum-based materials. This section describes vegetable oil-based polymer composites. It deals with the importance, classification, materials and methods, testing and analysis, performance and applications of vegetable oil-based polymer composites. Epoxidized soybean oil-based natural composite exhibits strong viscoelastic solid properties similar to those of synthetic rubber and can therefore replace them in many applications. Composite materials obtained by vinylation of epoxidation of soybean oil-based resins and fiber by styrene or acrylic acid, are used in the roofs, floor and walls of houses and low-rise commercial buildings. A resin made from soybean oil reinforced with glass fiber produced a new product used in parts of the latest tractors produced by John Deere. The demand for sustainable and renewable high performance, light weight materials are increasing exponentially.

Tsujimoto et al. (2010) studied the synthesis and properties of green nanocomposites from epoxidized natural oils and silane coupling agents [98]. Natural oil-based composites with good mechanical properties were prepared from an acrylate-modified soybean oil and natural fibers (flax and hemp fibers) [39]. Excellent gas barrier properties were found in laminated films of drying oil and Zein (corn) [99] [100]. Organic-inorganic composite coatings were developed using plant oils and metal (Ti and $\mathrm{Zn}$ ) oxides [101] [102].

Mosiewicki (2013) carried out review, which will concentrate on the use of vegetable oils as the base-materials for the production of polymer composites that incorporate inorganic and organic particles and fibers, both synthetic and natural in origin, and sized from the macro to the micro and nanoscale [103].

The last two decades have witnessed an exponential growth in the interest for using bio-derived products, which has been driven by the need for replacing petroleum based materials reducing the fuel consumption and, equally important, for producing materials with lower environmental impact. Vegetable oils constitute a rich source for many different polymers and polymer precursors and they are being considered for the production of "greener" composites.

Hong and Wool (2005) reported a novel bio-based composite material, suitable for electronic as well as automotive and aeronautical applications, was developed from soybean oils and keratin feather fibers (KF). This environmentally friendly, low-cost composite can be a substitute for petroleum-based composite materials. Keratin fibers are a hollow, light, and tough material and are compatible with several soybean (S) resins, such as acrylated epoxidized soybean oil (AESO) [104]. Just recently, research has been started to use oleo chemicals to build up matrices for natural fiber reinforced plastics. The use of natural fibers, such as flax, hemp, sisal, and yucca, is of increasing interest for various applications, among them the automotive industries, where the composites could be used in door pockets, covers, instrument panels, and sound insulation [105]. 
One of the key features in composite preparation consists of getting enough compatibility between the hydrophilic surface of the filler/fiber and the hydrophobic nature of plant-based resin. In this way the surface treatment and functionalization of the reinforcing materials [106] and the use of more reactive and polar functionalized triglyceride derivatives are two of the common approaches used in addressing these shortcomings. [107]. Amine cured combinations of epoxidized soybean oil and conventional epoxy resins, acrylated soybean oil alone or copolymerized with styrene and divinylbenzene, and more significantly polyurethane resins, prepared from polyols derived mainly from castor oil, have been extensively used to prepare composite materials with excellent mechanical properties and other useful target properties such as high impact resistance, good barrier properties or low dielectric constant with low expansion coefficients [108].

Khot et al. utilized an acrylated epoxidized soybean oil to produce glass fiber composites by resin transfer molding [5]. Depending on the fiber content, Young's moduli of 5.2 to $24.8 \mathrm{GPa}$ were measured for the composites bearing 35 and $50 \mathrm{wt} \%$ of GF, respectively, and tensile strengths of 129 - $463 \mathrm{MPa}$, for the same samples. Chandrashekhara et al. used an epoxidized soy oil based resin mixed with a commercial epoxy-amine system formulated for use in pultrusion [109].

The plasticizing effect of the dangling chains was also observed in other type of resins, and thus, it was reported by Husic et al. who prepared a soy-based polyol crosslinked with crude polymeric diphenyl methane diisocyanate (pMDI) and reinforced with up to $70 \mathrm{wt} \%$ of glass fiber fabric [110]. In this particular case, a short molecule polyol was added to increase the rigidity of the composite. Tensile and flexural properties were comparable to the results measured for an analogous glass fiber composite prepared with synthetic commercial polyurethane.

Henna et al. [111] used dicyclopentadiene (DCPD)-modified linseed oil cross-linked with DCDP as matrix for glass fiber composites. Increasing DCDP concentration lead to higher rubbery modulus (dynamic-mechanical measurements), since the network had fewer free dangling side-chains together with a lower molecular weight between crosslinking points, thus, producing a more rigid material. Similar arguments were used to explain the increase of Tg under those conditions. The incorporation of glass fibers did not change the position of the a transition as observed by the maximum of tand, but it reduced the height of the peak, since the material gained rigidity. Regarding the tensile properties, a 74.6 times higher Young's modulus was reported for the 60:40 (modified oil-DCDP) composite containing $40 \mathrm{wt} . \%$ of glass fibers. Ray et al. investigated the behavior of a blend of an epoxy resin and maleated castor oil co-reacted with an amine and filled with $10 \mathrm{wt} \%$ of fly ash [112].

Pfister and Larock presented an interesting comparison of the behavior of different cationically cured plant oils used as matrices of agricultural fibers [113]. They considered composites prepared from corn, soybean, fish, and linseed oils using up to $75 \mathrm{wt} \%$ of different natural fibers, corn stover, wheat straw, and switch-grass fibers. The composites showed a largely increased rigidity with respect to the unfilled thermosets, but they were also much more brittle. The Young's moduli reported were in the range of 1.6 - 2.3 GPa and the tensile strengths were between 5.5 and 11.3 MPa. One interesting observation was that higher degree of unsaturation of the natural oil lead to better thermal and mechanical properties of the composites, which can be linked to the higher crosslinking density that can be achieved in these materials. On the other hand, wheat straw fibers offered the best performance composites.

\subsection{Surfactants}

The basic way in which surfactants act is determined by their structure. With their hydrophilic head and hydrophobic tail, surfactant molecules interpose themselves between water and water-insoluble substances [114]. Surfactants are generally classified as being anionic, cationic, nonionic, or amphoteric surfactants depending on the type and charge of the hydrophilic groups [115]. Properties of surfactants are additionally governed by the alkyl chain length of their hydrophobic part: wetting agents (C8-C10), detergents (C12-C16), emulsifiers and softeners (C18-C22).

Many recently developed surfactants are an attempt to satisfy the modern consumer's desire for products to be "more natural". Like most plant-based products, surfactants derived from renewable raw materials (RRMs) are characterized by their positive impact on the environment, biodegradability, low or non-toxicity and innocuousness for human health. Vegetable oils furnish fatty chains (acids, alcohols, amines, esters) with a carbon chain length comprised between either 8 and 18 (saturated caprylic, capric, lauric, myristic, palmitic and stearic chains from tropical coconut, palm or palm kernel oils) or 18 and 22 (unsaturated oleic, linoleic, and linolenic chains 
from European rapeseed and sunflower oils) [116].

The main secondary product of oleochemistry is glycerol (coproduct of triglyceride hydrolysis and methanolysis processes), with a growing contribution from industrial vegetable oils. Within this context, the use of glycerol, as well as vegetable oils, as starting materials for the manufacture of surfactants represents a convenient strategy for the development of surface-active products entirely derived from oleochemistry. (poly)glycerol ester-type surfactants derived entirely from oleo chemicals that contribute to increase the value of the major secondary product of oleochemistry (i.e. glycerol). The basic manufacturing routes to important surfactants are laid out in Figure 4.

The surfactant with the highest volume-apart from soap-is still the petrochemical-based alkyl benzene sulfonate; however, in recent years a continuous trend towards surfactants based on renewable resources has become apparent.

Oleochemical surfactants will most likely be possible only by use of coconut, palm, and palm kernel oil because, according to the current state of the art, alcohols with short C-chains are required for the manufacture of surfactants. Substantial technological progress would need to be made in order to be able to also use European vegetable oils for surfactant production. This is not impossible given the progress that has, for example, recently been made in producing directly ethoxylated fatty acid methyl esters, indicating the applicability of oleochemical raw materials with longer carbon chains (C18), such as rapeseed oil and soya (soybean) oil (Hreczuch, 2001) [117].

\subsection{Paints, Coatings and Adhesives}

Vegetable oils have been used as binders or additives in paints and coatings for many centuries, dating back to the days of cave paintings. Although it is not certain whether linseed oil was used in paints in ancient Egypt, the Van Eyck brothers (1388-1441) are said to be the first to use linseed oil as a binder [6]. Oils belonging to the linolenic or conjugated acid groups, such as linseed, Tung and highly unsaturated winterized fish oil were of the prime interest to coating formulators. The primary use of vegetable oil in coatings is as drying oil. Vegetable oil derivatives as value added polymers/monomers have found enhanced applications as environment friendly hyperbranched or waterborne coating materials that offer improved performance and reduction or elimination in the use of volatile organic solvents [107].

Konwar et al. [118] prepared a polyester resin from seed oil of Mesua ferrea L. (also known as Ceylon ironwood, a hard wood tree from South Eastern Asia) reinforced with nanoclays in order to obtain a coating with improved performance of hardness, mechanical properties, impact and also chemical resistance, as well as gloss. Glycerolysis of the oil followed by reaction with anhydride and then, with a hydroxy-acid produced highly branched molecules. The carbonyl containing polyester resin was then reacted with a poly(amido-amine)-epoxy mixture in the presence of the nanoclay. Hydrogen bonding between the nanoplatelets and the resin occurred through the amine as well as carbonyl moieties present in the matrix. The addition of only $2.5 \mathrm{wt} \%$ nanoclays

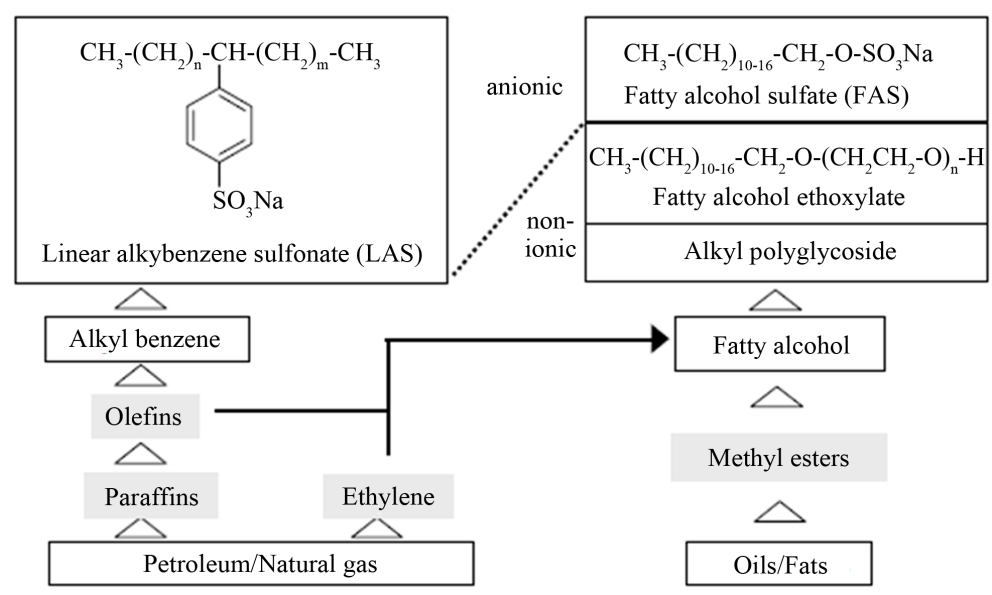

Figure 4. Production of surfactants and examples of products. 
improved the tensile strength from 2.7 to $7.1 \mathrm{MPa}$, and also the elongation at break from $24 \%$ to $145 \%$, while the impact hardness improved about $19 \%$. Chemical resistance to water and acids was improved with nanoclay addition up to a concentration of $2.5 \mathrm{wt} \%$, as well as thermal stability, gloss and hardness. The biodegradability of the films was also investigated using the broth culture technique with bacterial strains, resulting in larger bacterial growth in the nanocomposite than in the unfilled films.

Silica nanoparticles have been considered to improve the performance of a coating prepared from castor oil and an isocyanate alkyl triethoxy silane, further hydrolyzed to form an organic-inorganic hybrid coating [119]. Similarly, Sharmin et al. prepared a mixture of DGEBA epoxy and castor oil in a ratio of 70/30 by weight, and $10 \mathrm{wt} \%$ of prehydrolyzed TEOS [120]. After the reaction an organic-inorganic hybrid material was obtained, that was used to prepare films by reaction with TDI. The biohybrid coating was transparent, flexible, glossy and hard, showing to be scratch and impact resistant.

Epoxidized seed oils are used as reactive dilulents [121] and as toughening materials for commercial epoxy resins [122] [123]. Recently, Crivello and Narayan [124] demonstrated that epoxidized oils can be photopolymerized and have been used as cationic Uvcurable coatings. The coatings that obtained possess good adhesion and mechanical properties. However, epoxidized seed oils were associated with slow cure rate.

Among the triglyceride oils, linseed oil is commercially used as drying oil in paints and protective coatings due to presence of large amount of $\alpha$-linolenic acid compared to other vegetable oils, which has reactivity towards oxygen in air. The $\alpha$-linolenic acid content is around $51 \%-55 \%$ [125].

Arunjunai Raj Mahendran et al. (2012) [126] reported that an acrylated epoxidized linseed oil (AELO) was synthesized from epoxidized linseed oil through ring opening of the oxirane group using acrylic acid as ring opening agent. The occurrence of the acrylate group and the ring opening of oxirane group was monitored using FT-IR spectroscopy. The AELO was mixed with three different photoinitiators at two different concentrations. Wood surfaces were coated with the mixtures, subsequently cured under UV light and the resulting surface properties of the coated samples gloss, scratch resistance, solvent resistance, and coating adhesion were characterized.

Basturk et al. (2013) [127] reported the Organic-inorganic hybrid coating based on methacrylated/ phosphorylated epoxidized soybean oil were obtained by combining photo polymerization and sol-gel process. A series of novel methacrylated and phosphorylated epoxidized soybean oil/silica coating materials were prepared from tetraethoxysilane (TEOS), and acrylated soybean oil via sol-gel technique. Acrylated epoxidized soybean oil (AESO) is obtained by reacting epoxidized soybean oil (ESO) with methacrylic acid and vinyl phosphonic acid. The characterization of AESO was performed by NMR and IR spectroscopy. In liquid form UV-curable, clear hybrid coating materials were applied on polycarbonate substrates then cured UV-light. Finally their coating performances were determined by the various tests methods hardness, gloss, cross-cut adhesion tests, stressstrain test, gel content, contact angle. Thermogravimetric analysis (TGA) showed that the incorporation of solgel precursor into the resin leads to an enhancement in the thermal stability and also flame retardancy properties of the coated material.

Several inorganic precursors have been used to prepare organic/inorganic films with castor oil. Hybrid coatings have been prepared from epoxidized castor oil and the silicon-rich precursors tetraethoxysilane (TEOS) [128], glycidoxypropyltrimethoxysilane (GPTMS) [129] and the combination of aminopropyltriethoxysilane (APTES) and TEOS [130], in all cases improving substantially the hardness, maintaining the high adhesion to the surface and improving the corrosion protection. Hydroxylated castor oil (HCO) was also used to prepare hybrid coatings with the titania precursor titanium isopropoxide (TIP) [131] added in various proportions.

Bechi et al. (2013) examined the Two series of organic-inorganic hybrid films were prepared from epoxidized castor oil (ECO) and the inorganic precursor titanium(IV) isopropoxide (TIP), combined with silicon precursors, either 3-aminopropyltriethoxysilane (APTES) or tetraethoxysilane (TEOS) with different organic to inorganic proportions. New epoxidized castor-oil-based coating films were prepared with the combination of the sol-gel precursors APTES/TIP and TEOS/TIP. Hardness is improved in TEOS containing films whilst stronger films are obtained with the combination of a silicon-rich precursor with TIP [132].

Epoxidized seed oils are used extensively as an $\mathrm{HCl}$ scavenger for polyvinyl ether [133]. Epoxidized oils are also used as inks, however, epoxidized seed oils have found only modest application in specialty coating systems [134].

Crivello and Narayan (1992) demonstrated that epoxidized oils can be photo-polymerized and have been used as cationic UV curable coatings [124]. 


\subsection{Nanocomposites}

Polymeric materials from renewable resources are significantly important from industrial and economic view points. Inexpensive triglyceride plant oils have been used for the production of valuable resins. However, this oil based polymeric materials do not show properties of rigidity and strength required for structural applications by themselves; oils have been used as a toughening agent to produce interpenetrating networks. Recently, there has been enormous interest in organic-inorganic nanocomposites because of their unexpected hybrid properties derived from unique combinations of each component [135]. Concerning oil-based hybrid materials, composites with good mechanical properties were prepared from acrylate-modified soybean oil and natural fibers (flax and hemp fibers) [39]. Organic-inorganic hybrid coatings were developed using plant oils and metal (Ti and $\mathrm{Zr}$ ) oxides.

Very recently, Scientist developed green nanocomposites consisting of abundant natural resources, plant oils, and clay [136]. Curing of epoxidized plant oils in the presence of organophilic montmorillonite produced triglyceride-clay nanocomposites with homogeneous structure, in which the silicate layers of the clay were intercalated and randomly distributed in the polymer matrix [137].

Tsujimoto et al. (2003) developed green nanocomposite coatings showing excellent film properties and good biodegradability. The nanocomposite was prepared by an acid-catalyzed reaction of epoxidized plant oils and GPTMS (3-glycidoxypropyltrimethoxysilane), in which both oxirane groups of the epoxidized plant oils and GPTMS were copolymerized to produce an organic polymer matrix, and simultaneously forming a silica network. The covalent linkage between the organic and inorganic polymers would control the nanocomposite structure in nanoscales, leading to improvement of coating properties [137].

Liu et al. prepared networks from an epoxidized soybean oil (ESO) with nanoclay as reinforcement. While the tensile properties were improved up to $8 \mathrm{wt} \%$ of clay addition, higher concentrations lead to properties reduction. These results were explained by the immobilization (or partial immobilization) of the polymer chains due to the presence of the silicate layers below $8 \mathrm{wt} . \%$ and the inevitable aggregation that took place at a concentration of clay of $10 \mathrm{wt} \%$. The dynamic mechanical analysis showed that these materials had glass transition temperatures in the range of $11.8^{\circ} \mathrm{C}-20.7^{\circ} \mathrm{C}$ (from 0 and $5 \mathrm{wt} \%$ clay, respectively).

Uyama et al. used an epoxidized soybean oil (ESO) cationically crosslinked at high temperature in the presence of organically modified montmorillonite $(0-20 \mathrm{wt} \%)$ [136]. In this case, dynamic mechanical analysis (DMA) showed that the rubbery storage modulus increased with the clay concentration, but also the $\mathrm{Tg}$ shifted from $-2^{\circ} \mathrm{C}$ to $4{ }^{\circ} \mathrm{C}$ for samples bearing $0 \mathrm{wt} \%-15 \mathrm{wt} \%$ of clay, respectively. This change was explained as the result of the co-reaction of ESO with the modified clay, which together with the rigidity of the clay afforded freestanding flexible films instead of a soft one without structural value.

From Zhang et al. (2013), novel bio-based nanocomposites were prepared by blending surface modified natural clay with epoxidized soybean oil (ESO) and cyanate ester resin (CE). A convenient method was employed to modify the attapulgite (ATT) clay by adsorbing the poly(ethylene glycol) diglycidyl ether (PEGDE) onto the clay surface, which was confirmed by the appearance of a new peak of infrared spectroscopy due to hydrogen bonding and chelation. Scanning electron microscope (SEM) and transmission electron microscope (TEM) results showed that nano scaled ATT dispersed well in the blend of epoxidized soybean oil (ESO) before and after curing. The thermal-physical and mechanical properties were evaluated by dynamic mechanical analysis (DMA), TGA and tensile mechanical test. The nanocomposites showed higher glass transition temperature and modulus, and the tensile strength of the nanocomposites was reinforced as compared to that of ESO/CE blends [138].

Mohanty et al. [139]-[141] investigated the epoxidized linseed oil based epoxy materials; Adekunle et al. [142] and Mustata et al. [143] tested the performance of soybean oil composites, it is found that these renewable polymers could serve as an alternative to the traditional petroleum-based polymers through innovative design, because these novel bio-based polymers could be more cost-effective and eco-friendly than the existing petroleumbased polymers.

\subsection{Special Application}

Functional materials for special applications have also received much attention and thus several plant oil basedcomposite coatings, adhesives, processing aid and shape memory materials have been developed.

Kuriakose and Varghese (2003) reported the use of RBO/ERBO as a processing aid for improving the properties of carbon black-filled NR-CR blends. The blends prepared in different blend ratios were evaluated for their cure characteristics and physical properties. These properties were compared with those of control vulcanizates 
prepared using aromatic oil as the process aid [144].

A novel ESO-T-PR with excellent toughness and solder leaching resistance for paper CCI is synthesized and the modification reaction mechanism is addressed. The initial modification of PR (phenolic resin) is etherification of phenol hydroxyl catalyzed by tertiary amine. This process results in the grafting of ESC) with phenolic resin and is beneficial to increasing the crosslinking density of ESO-T-PR. Then unreacted oxirane in modified PR and some residue ESO are chemically linked with multi-amine to form longer flexible amine-curing EPO epoxy chain, which is the most important component for improving the toughness of PR. Both etherification and chain extension are necessary for preparing ESO-T-PR with good impact toughness and solder leaching resistance [144].

Fu et al. (2010) studied that ESO was used to increase the waterproof property of PLA and to reduce the residual monomer content. Epoxy and hydroxyl groups in ESO can initiate DL-lactide ring-opening polymerization. The main advantages of ESO and PLA are their abundance and environmental characteristics [145].

As a nontoxic and degradable plasticizer, ESO has been blended with PLA and other plastics to improve properties such as melt rheology and tensile strength etc. [146]-[149].

Epoxidized soybean oil (ESO) was applied as an additive for wheat gluten (WG) to modify the properties of the renewable and biodegradable natural polymer materials. Optimum intermolecular interactions and crosslinking between ESO chains and the WG matrix were achieved under alkaline conditions. The WGESO materials were heterogeneous on a scale of $20-30 \mathrm{~nm}$, but the homogeneity was improved upon increasing the amount of glycerol as a plasticizer in the materials. The combination of plasticization and crosslinking effects derived from ESO resulted in good retention in mechanical strength for the plasticized WGESO materials as compared to those without $10 \mathrm{wt} \%$ of mobile ESO additives. The hydrophobicity of the plasticized WG materials was also enhanced significantly by using the ESO additives [150].

Rana et al. studied the behavior of a hyperbranched polyurethane prepared from castor oil, polycaprolactone diol, butanediol and MDI [151]. The triglyceride contributed to the formation of a hyperbranched structure and helped to improve the dispersion of the carbon nanotubes (CNTs). The segmented polyurethanes obtained were semicrystalline with shape memory properties. The overall crystallinity increased with addition of $2 \mathrm{wt} \% \mathrm{CNT}$ or reducing the hard segments concentration, while the recovery of the original form was improved with increasing concentrations of CNT and hard segments.

Cakmakli et al. (2004) This work refers initially to the polymerization of linseed oil via peroxide linkages during the drying process in the air or under oxygen flow and then to the use of this polymeric peroxide in the polymerization of vinyl monomers to obtain graft copolymers containing oily segments leading to biodegradability and biocompatibility [152].

Author reported a novel synthetic approach for the chemical modification of vegetable oils to improve their thermo-oxidative and low-temperature stabilities. The chemical modification is carried out by epoxy ring opening of the epoxidized soybean oil by organic amines. Separate studies are in progress to determine the physical and performance properties of the products developed with optimized process. Scale-up process and cost calculations are outside the scope of this paper. These amine derivatives may serve the dual function of antioxidant and antiwear specialty chemicals in automotive and industrial applications [153].

\section{Conclusions}

With the examples of recent product innovations from oleochemistry, the successful development of environmentally compatible and powerful polymeric products in the sense of a sustainable development has been demonstrated. The combination of various vegetable raw materials to form new products will also be a challenge for research and development in the future, as is the development of additive for polymer or composite applications.

Use of Modified vegetable oil is a convenient way toward the goal of green chemistry, and is strongly recommended to use in polymer area. The examples cited above are impressive and provide a good insight into the field of utilization of vegetable oil as polymeric material. In order to achieve further development in this field, improved method and modification, which give rise to better properties and constitute a minimal hazard, should be used instead of the petrochemical based material.

\section{References}

[1] Wool, R.P. and Sun, X.S. (2005) Polymers and Composite Resins from Plant Oils in Bio-Based Polymers and Composites. Elsevier Academic Press, Burlington, 6-113. 
[2] Belgacem, M.N. and Gandini, A. (2008) Materials from Vegetable Oils: Major Sources, Properties and Applications. Monomers, Polymers and Composites from Renewable Resources, Chapter 3, 39-66. http://dx.doi.org/10.1016/B978-0-08-045316-3.00003-X

[3] Lu. Y. and Larock, R.C. (2009) Novel Polymeric Materials from Vegetable Oils and Vinyl Monomers: Preparation, Properties and Applications. ChemSusChem, 2, 136-147. http://dx.doi.org/10.1002/cssc.200800241

[4] Xia. Y. and Larock, R.C. (2010) Vegetable Oil-Based Polymeric Materials: Synthesis, Properties, and Applications. Green Chemistry, 12, 1893-1909. http://dx.doi.org/10.1039/c0gc00264j

[5] Khot, S.N., Lascala, J.J., Can, E., Morye, S.S., Williams, G.I., Palmese, G.R., et al. (2001) Development and Application of Triglyceride-Based Polymers and Composites. Journal of Applied Polymer Science, 82, 703-723. http://dx.doi.org/10.1002/app.1897

[6] Hui, Y.H. (1995) Bailey's Industrial Oil and Fats Products, Edible Oil and Fat Products: General Application. 5th Edition, Vol. 1, Wiley, Blackwell, 19-44.

[7] Guner, F.S., Yagci. Y. and Erciyes, A.T. (2006) Polymers from Triglyceride Oils. Progress in Polymer Science, 31, 633-670. http://dx.doi.org/10.1016/j.progpolymsci.2006.07.001

[8] Habib, F. and Bajpai, M. (2011) Synthesis and Characterization of Acrylated Epoxidized Soybean Oil for UV-Cured Coatings. Chemistry \& Chemical Technology, 5, 317-326.

[9] Ronda, J.C., et al. (2011) Vegetable Oils as Platform Chemicals for Polymer Synthesis. European Journal of Lipid Science and Technology, 113, 46-58. http://dx.doi.org/10.1002/ejlt.201000103

[10] Montero de Espinosa, L. and Meier, M.A.R. (2011) Plant Oils: The Perfect Renewable Resource for Polymer Science?! European Polymer Journal, 47, 837-852. http://dx.doi.org/10.1016/j.eurpolymj.2010.11.020

[11] Kayode, A., Christian, P., Adib, K. and Mikael, S. (2011) Mechanical and Viscoelastic Properties of Soybean Oil Thermoset Reinforced with Jute Fabrics and Carded Lyocell Fiber. Journal of Applied Polymer Science, 122, $2855-$ 2863. http://dx.doi.org/10.1002/app.34360

[12] Muturi, P., Wang, D. and Dirlikov, S. (1994) Epoxidized Vegetable Oils as Reactive Diluents I. Comparison of Vernonia, Epoxidized Soybean and Epoxidized Linseed Oils. Progress in Organic Coatings, 25, 85-94. http://dx.doi.org/10.1016/0300-9440(94)00504-4

[13] Ratna, D. and Banthia, A.T. (2000) Epoxidized Soybean Oil Toughened Epoxy Adhesive. Journal of Adhesion Science and Technology, 14, 15-25. http://dx.doi.org/10.1163/156856100742087

[14] Dirlikov, S.K., Frischinger, I., Islam, M.S. and Graham, J. (1990) Vernonia Oil: A New Reactive Monomer. Polymer Engineering \& Science, 62, 217-221.

[15] Mohanty, A.K., Misra, M., Drzal, L.T., et al. (2005) Natural Fibers, Biopolymer and Biocomposites. CRC Press, Boca Raton, 20-21.

[16] Bo, L., Yang, L.T., Dai, H.H. and Yi, A.H. (2008) Kinetic Studies on Oxirane Cleavage of Epoxidized Soybean Oil by Methanol and Characterization of Polyols. Journal of the American Oil Chemists' Society, 85, 113-117. http://dx.doi.org/10.1007/s11746-007-1187-5

[17] Meyer, P.P., Techaphattana, N., Manundawee, S., Sangkeaw, S., Junlakan, W. and Tongurai, C. (2008) Epoxidation of Soybean Oil and Jatropha Oil. Thammasat International Journal of Science and Technology, 13, 1-5.

[18] Rosli, W.D., Kumar, R.N., Mek, Z.S. and Hilmi, M.M. (2003) UV Radiation Curing of Epoxidized Palm Oil-Cycloaliphatic Diepoxide System Induced by Cationic Photoinitiator for Surface Coatings. European Polymer Journal, 39, 593-600. http://dx.doi.org/10.1016/S0014-3057(02)00241-0

[19] Klass, M. and Warwel, S. (1999) Complete and Partial Epoxidation of Plant Oils by Lipase-Catalyzed Perhydrolysis. Industrial Crops and Products, 9, 125-132. http://dx.doi.org/10.1016/S0926-6690(98)00023-5

[20] Xu, J.Y., Liu, Z.S., Erhan, S.Z. and Carriere, C.J. (2002) A Potential Biodegradable Rubber-Viscoelastic Properties of a Soybean Oil-Based Composite. Journal of the American Oil Chemists' Society, 79, 593-596. http://dx.doi.org/10.1007/s11746-002-0528-0

[21] Hiroaki, M., Robert, J.J., Amar, K.M., Manjusri, M. and Lawrence, T.D. (2006) Biobased Epoxy/Clay Nanocomposites as a New Matrix for CFRP. Composites Part A: Applied Science and Manufacturing, 37, 54-62. http://dx.doi.org/10.1016/j.compositesa.2005.05.014

[22] Hilker, I., Bothe, D., Pruss, J. and Warnecke, J. (2001) Chemo-Enzymatic Epoxidation of Unsaturated Plant Oils. Chemical Engineering Science, 56, 427-432. http://dx.doi.org/10.1016/S0009-2509(00)00245-1

[23] Barrett, L.W., Sperling, L.H. and Murphy, C.J. (1993) Naturally Functionalized Triglyceride Oils in Interpenetrating Polymer Networks. Journal of the American Oil Chemists' Society, 70, 523-534. http://dx.doi.org/10.1007/BF02542588

[24] Qureshi, S., Manson, J.A., Sperling, L.H. and Murphy, C.J. (1983) In: Carraher, C.E. and Sperling, L.H., Eds., Polymer 
Application of Renewable Resources Materials. Plenum Press, New York, 249-271.

[25] United States Department of Agriculture (2012) Oilseeds: World Markets and Trade Archives.

[26] Corma, A., Iborra, S. and Velty, A. (2007) Chemical Routes for the Transformation of Biomass into Chemicals. Chemical Reviews, 107, 2411-2502. http://dx.doi.org/10.1021/cr050989d

[27] Biermann, U., Bornscheuer, U., Meier, M.A.R., Metzger, J.O. and Schafer, H.J. (2011) Oils and Fats as Renewable Raw Materials in Chemistry. Angewandte Chemie International Edition, 50, 3854-3871. http://dx.doi.org/10.1002/anie.201002767

[28] Battersby, N.S., Pack, S.E. and Watkinson, R.J. (1992) A Correlation between the Biodegradability of Oil Products in the CEC L-33-T-82 and Modified Sturm Tests. Chemosphere, 24, 1998-2000. http://dx.doi.org/10.1016/0045-6535(92)90247-O

[29] Shashidhara, Y.M. and Jayaram, S.R. (2010) Vegetable Oils as a Potential Cutting Fluid—An Evolution. Tribology International, 43, 1073-1081. http://dx.doi.org/10.1016/j.triboint.2009.12.065

[30] Matthew, T.S., Nader, S., Bigyan, A. and Lambert, A.D. (2007) Influence of Fatty Acid Composition on the Tribological Performance of Two Vegetable-Based Lubricants. Journal of Synthetic Lubrication, 24, 101-110. http://dx.doi.org/10.1002/jsl.32

[31] Joseph, P.V. (2007) Study of Some Non-Edible Vegetable Oils of Indian Origin for Lubricant Application. Journal of Synthetic Lubrication, 24, 181-197. http://dx.doi.org/10.1002/jsl.39

[32] Sivasankaran, G.A. (1988) Jojoba-Oil-Based Two Stroke Gasoline Engine Lubricant. Tribology International, 21, 327333. http://dx.doi.org/10.1016/0301-679X(88)90109-0

[33] Bhatnagar, A.H. (2006) HFRR Studies on Methyl Ester of Non Edible Vegetable Oils. Energy \& Fuels, 20, $1341-1344$. http://dx.doi.org/10.1021/ef0503818

[34] Singh, A.K., et al. (2006) Metal Working Fluids from Vegetable Fluids. Journal of Synthetic Lubrication, 123, 167176. http://dx.doi.org/10.1002/jsl.19

[35] Loredana, P. (2008) Base Stock Oils for Lubricants from Mixtures of Corn Oil and Synthetic Diesters. Journal of the American Oil Chemists' Society, 85, 71-76. http://dx.doi.org/10.1007/s11746-007-1156-Z

[36] Borden, G.W. and Smith, O.W. (1997) Radiation Curable Inks and Coatings. US Patent No. 4025477.

[37] Kirschenbauer, H.G. (1960) Fats and Oils: An Outline of Their Chemistry and Technology. Reinhold, New York.

[38] Williams, G.I. and Wool, R.P. (2000) Composites from Natural Fibers and Soy Oil Resins. Applied Composite Materials, 7, 421-423. http://dx.doi.org/10.1023/A:1026583404899

[39] Bunker, S.P. and Wool, R.P. (2002) Synthesis and Characterization of Monomers and Polymers for Adhesives from Methyl Oleate. Journal of Polymer Science Part A: Polymer Chemistry, 40, 451-458. http://dx.doi.org/10.1002/pola.10130

[40] Larock, R.C., Dong, X.Y., Chung, S., Reddy, C.K. and Ehlers, L.E. (2001) Preparation of Conjugated Soybean Oil and Other Natural Oils and Fatty Acids by Homogeneous Transition Metal Catalysis. Journal of the American Oil Chemists' Society, 78, 447-453. http://dx.doi.org/10.1007/s11746-001-0284-1

[41] Meiorin, C., Aranguren, M.I. and Mosiewicki, M.A. (2012) Vegetable Oil Based Thermoset Copolymers with Shape Memory Behavior and Damping Capacity. Polymer International, 64, 735-742. http://dx.doi.org/10.1002/pi.3231

[42] Meiorin, C., Aranguren, M.I. and Mosiewicki, M.A. (2012) Smart and Structural Thermosets from Cationic Copolymerization of a Vegetable Oil. Journal of Applied Polymer Science, 124, 5071-5708.

[43] Li, F.K. and Larock, R.C. (2003) Synthesis, Structure and Properties of New Tung Oil-Styrene-Divinylbenzene Copolymers Prepared by Thermal Polymerization. Biomacromolecules, 4, 1018-1025. http://dx.doi.org/10.1021/bm034049j

[44] Mosiewicki, M.A., Arciprete, G.A., Aranguren, M.I. and Marcovich, N.E. (2009) Polyurethane Foams Obtained from Castor Oil Based Polyol and Filled with Wood Flour. Journal of Composite Materials, 43, 3057-3072. http://dx.doi.org/10.1177/0021998309345342

[45] Wik, V.M., Aranguren, M.I. and Mosiewicki, M.A. (2011) Castor Oil-Based Polyurethanes Containing Cellulose Nanocrystals. Polymer Engineering \& Science, 51, 1389-1396. http://dx.doi.org/10.1002/pen.21939

[46] La Scala, J. and Wool, R.P. (2002) Effect of FA Composition on Epoxidation Kinetics of TAG. Journal of the American Oil Chemists' Society, 79, 373-378. http://dx.doi.org/10.1007/s11746-002-0491-9

[47] Petrovic, Z.S., Zlatanic, A., Lava, C.C. and Sinadinovic-Fiser, S. (2002) Epoxidation of Soybean Oil in Toluene with Peroxoacetic and Peroxoformic Acids-Kinetics and Side Reactions. European Journal of Lipid Science and Technology, 104, 293-299. http://dx.doi.org/10.1002/1438-9312(200205)104:5<293::AID-EJLT293>3.0.CO;2-W

[48] Lu, J., Khot, S. and Wool, R.P. (2005) New Sheet Molding Compounds Resins from Soybean Oil. I. Synthesis and Characterization. Polymer, 46, 71-80. http://dx.doi.org/10.1016/j.polymer.2004.10.060 
[49] Anderson, D.F. and Mckenzie, D.A. (1970) Mechanism of the Thermal Stabilization of Poly(vinyl chloride) with Metal Carboxylates and Epoxy Plasticizers. Journal of Polymer Science Part A-1: Polymer Chemistry, 8, 2905-2922. http://dx.doi.org/10.1002/pol.1970.150081016

[50] Helena, W., Rolf, L. and Theo, M. (2001) Lubricant Base Fluids Based on Renewable Raw Materials Their Catalytic Manufacture and Modification. Applied Catalysis A: General, 221, 429-442. http://dx.doi.org/10.1016/S0926-860X(01)00891-2

[51] Ravasio, N., et al. (2002) Environmetal Friendly Lubricants through Slective Hydrogenation of Rapeseed Oil over Supported Copper Catalyst. Applied Catalysis A: General, 233, 1-6.

[52] Piyush, S.L. (2007) Green Approach for the Preparation of Biodegradable Lubricant Base Stock from Epoxidised Vegetable Oil. Applied Catalysis B: Environmental, 69, 207-212. http://dx.doi.org/10.1016/j.apcatb.2006.06.016

[53] Adhvaryu, A. (2004) Tribological Studies of Thermally and Chemically Modified Vegetable Oils for Use as Environmentally Friendly Lubricants. Wear, 257, 359-367. http://dx.doi.org/10.1016/j.wear.2004.01.005

[54] Mehta, B., Kathalewar, M. and Sabnis, A. (2014) Benzyl Ester of Dehydrated Castor Oil Fatty Acid as Plasticizer for Poly(vinyl chloride). Polymer International, 63, 1456-1464. http://dx.doi.org/10.1002/pi.4641

[55] Frye, A.H. and Horst, R.W. (1959) The Mechanism of Poly(vinyl chloride) Stabilization by Barium, Cadmium, and Zinc Carboxylates. I. Infrared Studies. Journal of Polymer Science, 40, 419-431. http://dx.doi.org/10.1002/pol.1959.1204013712

[56] Benaniba, M.T., Belhaneche-Bensemrab, N. and Gelbard, G. (2001) Stabilizing Effect of Epoxidized Sunflower Oil on the Thermal Degradation of Poly(Vinyl Chloride). Polymer Degradation and Stability, 74, 501-505. http://dx.doi.org/10.1016/S0141-3910(01)00170-7

[57] Benanibaa, M.T., Belhaneche-Bensemrab, N. and Gelbardc, G. (2003) Stabilization of PVC by Epoxidized Sunflower Oil in the Presence of Zinc and Calcium Stearates. Polymer Degradation and Stability, 82, 245-249. http://dx.doi.org/10.1016/S0141-3910(03)00178-2

[58] Lerke, G., Lerke, I. and Szymanski, W. (1983) Stabilization of Gamma-Irradiated Poly(vinyl chloride) by Epoxy Compounds. III. Conjugated Double Bonds and Degree of Unsaturation in Gamma-Irradiated PVC-Stabilizer Mixtures. Journal of Applied Polymer Science, 28, 519-529. http://dx.doi.org/10.1002/app.1983.070280208

[59] Housel, S.D. (1985) Additives Help Hold Color in Gamma-Sterilized PVC. Plastics Engineering, 47-49.

[60] Troitskii, B.B., Troitskaya, L.S. and Denisova, V.N. (1988) Prept. Int. 31 Microsymp Macromolecules "Polyvinyl Cholride", Prague, 69

[61] Wypych, J. (1986) Polyvinyl Chloride Stabilization. Elsevier, Amsterdam.

[62] Owen, E.D. (1984) Degradation and Stabilization of PVC. Elsevier Applied Science Publishers, London, 21-80. http://dx.doi.org/10.1007/978-94-009-5618-6

[63] Okieimen, F.E. and Ebhoaye, J.E. (1993) Thermal Dehydrochlorination of PVC in the Presence of Rubber Seed Oil. Die Angewandte Makromolekulare Chemie, 206, 11-20. http://dx.doi.org/10.1002/apmc.1993.052060102

[64] Okieimen, F.E. (2002) Studies in the Utilisation of Epoxidized Vegetable Oils as Thermal Stabiliser for Poly(vinyl chloride). Industrial Crops and Products, 15, 71-75. http://dx.doi.org/10.1016/S0926-6690(01)00097-8

[65] Okieimen, F.E. and Ebhoaye, J.E. (1993) Studies in the Thermal Degradation of Poly(Vinyl Chloride). Journal of Applied Polymer Science, 48, 1853-1858. http://dx.doi.org/10.1002/app.1993.070481019

[66] Badra, B. and Mohamed, T.B. (2008) Effects of Epoxidized Sunflower Oil on the Mechanical and Dynamical Analysis of the Plasticized Poly(vinyl chloride). Journal of Applied Polymer Science, 107, 3442-3450. http://dx.doi.org/10.1002/app.27458

[67] Taghizadeh, M.T., Nalbandi, N. and Bahadori, A. (2008) Stabilizing Effect of Epoxidized Sunflower Oil as a Secondary Stabilizer for $\mathrm{Ca} / \mathrm{Hg}$ Stabilized PVC. Express Polymer Letters, 2, 65-76. http://dx.doi.org/10.3144/expresspolymlett.2008.9

[68] Randles, S.J. and Wright, M. (1992) Environmentally Considerate Ester Lubricants for the Automotive and Engineering Industries. Journal of Synthetic Lubrication, 9, 145-161. http://dx.doi.org/10.1002/jsl.3000090205

[69] Naughton, F.C. (1974) Production, Chemistry, and Commercial Applications of Various Chemicals from Castor Oil. Journal of the American Oil Chemists Society, 51, 65-71.

[70] Gast, L.E., Croston, C.B., Schneider, W.J. and Teeter, H.M. (1954) Synthetic Lubricants from Polyhydroxystearic Acids. Journal of Industrial and Engineering Chemistry, 46, 2205-2208. http://dx.doi.org/10.1021/ie50538a056

[71] Becker, R. and Knorr, A. (1996) An Evaluation of Antioxidants for Vegetable Oils at Elevated Temperatures. Lubrication Science, 8, 95-117. http://dx.doi.org/10.1002/ls.3010080202

[72] Uosukainen, E., Linko, Y.Y., Lamasa, M., Tervakangas, T. and Linko, P. (1998) Transesterification of Trimethylol- 
propane and Rapeseed Oil Methyl Ester to Environmentally Acceptable lubricants. Journal of the American Oil Chemists' Society, 75, 1557-1563. http://dx.doi.org/10.1007/s11746-998-0094-8

[73] Johansson, L.E. and Lundin, S.T. (1979) Copper Catalysts in the Selective Hydrogenation of Soybean and Rapeseed Oils: I. The Activity of the Copper Chromite Catalyst. Journal of the American Oil Chemists' Society, 56, 974-980. http://dx.doi.org/10.1007/BF02674147

[74] Sinadinovic-Fiser, S., Jankovic, M. and Petrovic, Z.S. (2001) Kinetics of in Situ Epoxidation of Soybean Oil in Bulk Catalyzed by Ion Exchange Resin. Journal of the American Oil Chemists' Society, 78, 725-731. http://dx.doi.org/10.1007/s11746-001-0333-9

[75] Adhvaryu, A. and Erhan, S.Z. (2002) Epoxidized Soybean Oil as a Potential Source of High-Temperature Lubricants. Industrial Crops and Products, 15, 247-254. http://dx.doi.org/10.1016/S0926-6690(01)00120-0

[76] Padwa, A. and Murphree, S.S. (2006) Epoxides and Aziridines-A Mini Review. Arkivoc, 3, 6-33. http://dx.doi.org/10.3998/ark.5550190.0007.302

[77] Rios, L.A., Weckes, P.P., Schuster, H. and Hoelderich, W.F. (2005) Resin Catalyzed Alcoholysis of Epoxidized Fatty Esters: Effect of the Alcohol and the Resin Structures. Applied Catalysis A: General, 284, 155-161. http://dx.doi.org/10.1016/j.apcata.2005.01.031

[78] Lathi, P.S. and Mattiasson, B. (2007) Green Approach for the Preparation of Biodegradable Lubricant Base Stock from Epoxidized Vegetable Oil. Applied Catalysis B: Environmental, 69, 207-212. http://dx.doi.org/10.1016/j.apcatb.2006.06.016

[79] Fox, N.J. and Stachowiak, G.W. (2007) Vegetable Oil-Based Lubricants-A Review of Oxidation. Tribology International, 40, 1035-1046. http://dx.doi.org/10.1016/j.triboint.2006.10.001

[80] Campanella, A., Rustoy, E., Baldessari, A. and Baltanas, M.A. (2010) Lubricants from Chemically Modified Vegetable Oils. Bioresource Technology, 101, 245-254. http://dx.doi.org/10.1016/j.biortech.2009.08.035

[81] Wu, X., Zhang, X., Yang, S., Chen, H. and Wang, D. (2000) The Study of Epoxidized Rapeseed Oil Used as a Potential Biodegradable Lubricant. Journal of the American Oil Chemists' Society, 77, 561-563. http://dx.doi.org/10.1007/s11746-000-0089-2

[82] Hwang, H. and Erhan, S.Z. (2001) Modification of Epoxidized Soybean Oil for Lubricant Formulations with Improved Oxidative Stability and Low Pour Point. Journal of the American Oil Chemists' Society, 78, 1179-1184. http://dx.doi.org/10.1007/s11745-001-0410-0

[83] Hwang, H. and Erhan, S.Z. (2006) Synthetic Lubricant Basestocks from Epoxidized Soybean Oil and Guerbet Alcohols. Industrial Crops and Products, 23, 311-317. http://dx.doi.org/10.1016/j.indcrop.2005.09.002

[84] Białecka-Florjanczyk, E. and Florjanczyk, Z. (2007) Solubility of Plasticizers, Polymers and Environmental Pollution. Chapter 22, Thermodynamics, Solubility and Environmental Issues, 397-407. http://dx.doi.org/10.1016/B978-044452707-3/50024-0

[85] Rahman, M. and Brazel, C.S. (2004) The Plasticizer Market: An Assessment of Traditional Plasticizers and Research Trends to Meet New Challenges. Progress in Polymer Science, 29, 1223-1248. http://dx.doi.org/10.1016/j.progpolymsci.2004.10.001

[86] Baltacioğlu, H. and Balkose, D. (1999) Effect of Zinc Stearate and/or Epoxidized Soybean Oil on Gelation and Thermal Stability of PVC-DOP Plastigels. Journal of Applied Polymer Science, 74, 2488-2498. http://dx.doi.org/10.1002/(SICI)1097-4628(19991205)74:10<2488::AID-APP18>3.0.CO;2-B

[87] Krauskopf, L.G. and Godwin, A. (2005) Plasticizers. In: Wilkes, C.E., Summers, J.W. and Daniels, C.A., Eds., PVC Handbook, Hanser, Munich, 173-193.

[88] Wypych, G. (2004) Handbook of Plasticizers. Chem Tech, Toronto, New York, 687.

[89] Vieira, M.G.A., Silva, M.A.D., Santos, L.O.D. and Beppu, M.M. (2011) Natural-Based Plasticizers and Biopolymer Films a Review. European Polymer Journal, 47, 254-263. http://dx.doi.org/10.1016/j.eurpolymj.2010.12.011

[90] Suarez Palacios, O.Y., et al. (2014) Multicriteria Optimization of Production Conditions for a New Phthalate-Free PVC Plasticizer. Journal of Industrial and Engineering Chemistry, 20, 1985-1992. http://dx.doi.org/10.1016/j.jiec.2013.09.021

[91] Formo, M.W. (1995) Industrial Use of Soybean Oil. In: Barnes, P.J. and Associates, Eds., Proceedings of the 21 st World Congress of the International Society of Fat Research (ISF), The Hague, Barnes, P.J. and Associates, Hague, 519-527.

[92] Boussoum, M.O., Atek, D. and Belhaneche-Bensemra, N. (2006) Interactions between Poly(vinyl chloride) Stabilised with Epoxidised Sunflower Oil and Food Stimulants. Polymer Degradation and Stability, 91, 579-584. http://dx.doi.org/10.1016/j.polymdegradstab.2005.05.036

[93] Karmalm, P., Hjertberg, T., Jansson, A., Dahl, R. and Ankner, K, (2009) Network Formation by Epoxidised Soybean 
Oil in Plastisol Poly(Vinyl Chloride). Polymer Degradation and Stability, 94, 1986-1990. http://dx.doi.org/10.1016/j.polymdegradstab.2009.07.029

[94] da Silva, M.A., Vieira, M.G.A., Maçumoto, A.C.G. and Beppu, M.M. (2011) Polyvinylchloride (PVC) and Natural Rubber Films Plasticized with a Natural Polymeric Plasticizer Obtained through Polyesterification of Rice Fatty Acid. Polymer Testing, 30, 478-484. http://dx.doi.org/10.1016/j.polymertesting.2011.03.008

[95] Greco, A., Brunetti, D., Renna, G., Mele, G. and Maffezzoli, A. (2010) Plasticizer for Poly(vinyl chloride) from Cardanol as a Renewable Resource Material. Polymer Degradation and Stability, 95, 2169-2174. http://dx.doi.org/10.1016/j.polymdegradstab.2010.06.001

[96] Fenollar, O., Garcia-Sanoguera, D., Sanchez-Nacher, L., Lopez, J. and Balart, R. (2010) Effect of the Epoxidized Linseed Oil Concentration as Natural Plasticizer in Vinyl Plastisols. Journal of Materials Science, 45, 4406-4413. http://dx.doi.org/10.1007/s10853-010-4520-6

[97] Al-Mulla, E.A.J., Wan Yunus, W.M.Z., Bt Ibrahim, N.A. and Rahman, M.Z.A. (2010) Properties of Epoxidized Palm Oil Plasticized Polytlactic Acid. Journal of Materials Science, 45, 1942-1946. http://dx.doi.org/10.1007/s10853-009-4185-1

[98] Tsujimoto, T., Uyama, H. and Kobayashi, S. (2010) Synthesis of High-Performance Green Nanocomposites from Renewable Natural Oils. Polymer Degradation and Stability, 95, 1399-1405. http://dx.doi.org/10.1016/j.polymdegradstab.2010.01.016

[99] Bhabhe, M.D. and Athawale, V.D. (1997) Chemoenzymatic Synthesis of Oil-Modified Acrylic Monomers as Reactive Diluents for High Solids Coatings. Progress in Organic Coatings, 30, 207-211. http://dx.doi.org/10.1016/S0300-9440(96)00671-6

[100] Rakotonirainy, A.M. and Padua, G.W. (2001) Effects of Lamination and Coating with Drying Oils on Tensile and Barrier Properties of Zein Films. Journal of Agricultural and Food Chemistry, 49, 2860-2863. http://dx.doi.org/10.1021/jf000845u

[101] Wold, C.R. and Soucek, M.D. (2000) Viscoelastic and Thermal Properties of Linseed Oil-Based Ceramer Coatings. Macromolecular Chemistry and Physics, 201, 382-392. http://dx.doi.org/10.1002/(SICI)1521-3935(20000201)201:3<382::AID-MACP382>3.0.CO;2-9

[102] Deffar, D., Teng, G. and Soucek, M.D. (2001) Comparison of Titanium-Oxo-Clusters Derived from Sol-Gel Precursors with $\mathrm{TiO}_{2}$ Nanoparticles in Drying Oil Based Ceramer Coatings. Macromolecular Materials and Engineering, 286, 204-215. http://dx.doi.org/10.1002/1439-2054(20010401)286:4<204::AID-MAME204>3.0.CO;2-4

[103] Mosiewicki, M.A. and Aranguren, M.I. (2013) A Short Review on Novel Biocomposites Based on Plant Oil Precursors. European Polymer Journal, 49, 1243-1256. http://dx.doi.org/10.1016/j.eurpolymj.2013.02.034

[104] Hong, C.K. and Wool, R.P. (2005) Development of a Bio-Based Composite Material from Soybean Oil and Keratin Fibers. Journal of Applied Polymer Science, 95, 1524-1538. http://dx.doi.org/10.1002/app.21044

[105] Dahlke, B., Larbig, H., Scherzer, H.D. and Poltrock. R. (1998) Natural Fiber Reinforced Foams Based on Renewable Resources for Automotive Interior Applications. Journal of Cellular Plastics, 34, 361-379.

[106] Blacker, J.J., Lee, K.Y. and Bismarck, A. (2011) Hierarchical Composites Made Entirely from Renewable Resources. Journal of Biobased Materials and Bioenergy, 5, 1-16.

[107] Lligadas, G., Ronda, J.C., Galia, M. and Diz, V.C. (2013) Renewable Polymeric Materials from Vegetable Oils: A Perspective. Materials Today, 16, 337-343. http://dx.doi.org/10.1016/j.mattod.2013.08.016

[108] Adekunle, K. et al. (2011) Mechanical and Viscoelastic Properties of Soybean Oil Thermoset Reinforced with Jute Fabrics and Carded Lyocell Fiber. Journal of Applied Polymer Science, 122, 2855-2863. http://dx.doi.org/10.1002/app.34360

[109] Chandrashekhara, K., Sundararaman, S., Flanigan, V. and Kapila, S. (2005) Affordable Composites Using Renewable Materials. Materials Science and Engineering: A, 412, 2-6. http://dx.doi.org/10.1016/j.msea.2005.08.066

[110] Husic, S., Javni, I. and Petrovic, Z.S. (2005) Thermal and Mechanical Properties of Glass Reinforced Soy-Based Polyurethane Composites. Composites Science and Technology, 65, 19-25. http://dx.doi.org/10.1016/j.compscitech.2004.05.020

[111] Henna, P.H., Kessler, M.R. and Larock, R.C. (2008) Fabrication and Properties of Vegetable-Oil-Based Glass Fiber Composites by Ring-Opening Metathesis Polymerization. Macromolecular Materials and Engineering, 293, 979-990. http://dx.doi.org/10.1002/mame.200800202

[112] Ray, D., Ghorui, S., Bandyopadhyay, N.R., Sengupta, S. and Kar, T. (2012) New Materials from Maleated Castor Oil/Epoxy Resin Blend Reinforced with Fly Ash. Industrial \& Engineering Chemistry Research, 51, 2603-2608. http://dx.doi.org/10.1021/ie201472u

[113] Pfister, D.P. and Larock, R.C. (2012) Cationically-Cured Natural Oil-Based Green Composites: Effect of the Natural Oil and the Agricultural Fiber. Journal of Applied Polymer Science, 123, 1392-1400. 
http://dx.doi.org/10.1002/app.33636

[114] Karlheinz, Hill. (2000) Fats and Oils as Oleochemical Raw Materials. Pure and Applied Chemistry, 72, $1255-1264$.

[115] Falbe, J. (1987) Surfactants in Consumer Products: Theory, Technology, Applications. Springer, Heidelberg, 475. http://dx.doi.org/10.1007/978-3-642-71545-7

[116] Belgacem, M.N. and Gandini, A. (2008) Monomers, Polymers and Composites from Renewable Resources. Elsevier, Amsterdam, 154-178.

[117] Hreczuch, W. (2001) Ethoxylated Rapeseed Oil Acid Methyl Esters as New Ingredients for Detergent Formulations. Tenside Surfactants Detergents, 38, 72-79.

[118] Konwar, U., Karak, N. and Mandal, M. (2009) Mesua ferrea L. Seed Oil Based Highly Thermostable and Biodegradable Polyester/Clay Nanocomposites. Polymer Degradation and Stability, 94, 2221-2230. http://dx.doi.org/10.1016/j.polymdegradstab.2009.09.001

[119] Mulazim, Y., Cakmakc, E. and Kahraman, M.V. (2011) Preparation of Photo Curable Highly Hydrophobic Coatings Using a Modified Castor Oil Derivative as a Sol-Gel Component. Progress in Organic Coatings, 72, 394-401. http://dx.doi.org/10.1016/j.porgcoat.2011.05.012

[120] Sharmin, E., Akram, D., Ghosal, A., Rahman, O., Zafar, F. and Ahmad, S. (2011) Preparation and Characterization of Nanostructured Biohybrid. Progress in Organic Coatings, 72, 469-472. http://dx.doi.org/10.1016/j.porgcoat.2011.06.004

[121] Qureshi, S., Manson, J.A., Michel, J.C, Hertzberg, R.W. and Sperling, L.H. (1984) In: Labana, S.S. and Dickie, R.A., Eds., Characterization of Highly Crosslinked Polymers, ASC Symposium Series 243, American Chemical Society, Washington DC, 8.

[122] Fernandez, A.M., Manson, J.A. and Sperling, L.H. (1986) Simultaneous Interpenetrating Networks Based on Vernonia Oil Polyesters and Polystyrene: II. A Comparison of the Reactivities of Vernonia Oil and Castor Oil toward the Formation of Polyesters. In: Carraher, C. and Sperling, L.H., Eds., Renewable Resource Materials, Plenum Press, New York, 177-186. http://dx.doi.org/10.1007/978-1-4613-2205-4_15

[123] Frischinger, I. and Dirlikov, S. (1991) Two-Phase Interpenetrating Epoxy Thermosets That Contain Epoxidized Triglyceride Oils. Interpenetrating Polymer Networks, 25, 517-538.

[124] Crivello, J.V. and Narayan, R. (1992) Epoxidized Triglycerides as Renewable Monomers in Photoinitiated Cationic Polymerization. Chemistry of Materials, 4, 692-699. http://dx.doi.org/10.1021/cm00021a036

[125] Vereshagin, A.G. and Novitskaya, G.V. (1965) The Triglyceride Composition of Linseed Oil. Journal of the American Oil Chemists Society, 42, 970-974. http://dx.doi.org/10.1007/BF02632457

[126] Mahendran, A.R., Wuzella, G., Aust, N., Kandelbaue, A. and Müllera, U. (2012) Photo Crosslinkable Modified Vegetable Oil Based Resin for Wood Surface Coating Application. Progress in Organic Coatings, 74, 697-704. http://dx.doi.org/10.1016/j.porgcoat.2011.09.027

[127] Basturk, E., Inan, T. and Gungora, A. (2013) Flame Retardant UV-Curable Acrylated Epoxidized Soybean Oil Based Organic-Inorganic Hybrid Coating. Progress in Organic Coatings, 76, 985-992. http://dx.doi.org/10.1016/i.porgcoat.2012.10.007

[128] de Luca, M.A., Martinelli, M., Jacobi, M.M., Becker, P.L. and Ferrao, M.F. (2006) Ceramer Coatings from Castor Oil or Epoxidized Castor Oil and Tetraethoxysilane. Journal of the American Oil Chemists' Society, 83, 147-151. http://dx.doi.org/10.1007/s11746-006-1187-x

[129] de Luca, M.A., Martinelli, M. and Barbieri, C.T. (2009) Hybrid Films Synthesised from Epoxidised Castor Oil, $\gamma$-Glycidoxypropyltrimethoxysilane and Tetraethoxysilane. Progress in Organic Coatings, 65, 375-380. http://dx.doi.org/10.1016/i.porgcoat.2009.03.002

[130] Becchi, D.M., de Luca, M.A., Martinelli, M. and Mitidieri, S. (2011) Organic-Inorganic Coatings Based on Epoxidised Castor Oil/APTES/TEOS. Journal of the American Oil Chemists' Society, 88, 101-109. http://dx.doi.org/10.1007/s11746-010-1651-5

[131] Martinelli, M., de Luca, M.A., Bechi, D.M. and Mitidieri, S. (2009) Hybrid Films Based on Hydroxylated Castor Oil and Titanium(IV) Isopropoxide. Journal of Sol-Gel Science and Technology, 52, 202-209. http://dx.doi.org/10.1007/s10971-009-2044-9

[132] Bechi, D.M., de Luca, M.A., Martinellia, M. and Mitidieri, S. (2013) Organic-Inorganic Coatings Based on Epoxidized Castor Oil with APTES/TIP and TEOS/TIP. Progress in Organic Coatings, 76, 736-742. http://dx.doi.org/10.1016/i.porgcoat.2013.01.004

[133] Gachter, R. (1987) Plastics Additives Handbook. 2nd Edition, Hanser Publishers, Munich, 282.

[134] Mathur, A.M., Narayanan, V. and Scranton, A.B. (1998) UV Curable Epoxidized Oils with Vinylethers as Reactive Diluents. Proceedings of the 1998 Radtech International Conference, 486. 
[135] Sanchez, C., Soler-Illia, G.J.A.A., Ribot, F., Lalot, T., Mayer, C.R. and Cabuil, V. (2001) Designed Hybrid OrganicInorganic Nanocomposites from Functional Nanobuilding Blocks. Chemistry of Materials, 13, 3061-3083. http://dx.doi.org/10.1021/cm011061e

[136] Uyama, H., Kuwabara, M., Tsujimoto, T., Nakano, M., Usuki, A. and Kobayashi, S. (2003) Green Nanocomposites from Renewable Resources: Plant Oil-Clay Hybrid Materials. Chemistry of Materials, 15, 2492-2494. http://dx.doi.org/10.1021/cm0340227

[137] Tsujimoto, T., Uyama, H. and Kobayashi, S. (2003) Green Nanocomposites from Renewable Resources: Biodegradable Plant Oil-Silica Hybrid Coatings. Macromolecular Rapid Communications, 24, 711-714. http://dx.doi.org/10.1002/marc.200350015

[138] Zhang, J., Hu, S., Zhan, G., Tang, X. and Yu, Y. (2013) Biobased Nanocomposites from Clay Modified Blend of Epoxidized Soybean Oil and Cyanate Ester Resin. Progress in Organic Coatings, 76, 1683-1690. http://dx.doi.org/10.1016/j.porgcoat.2013.07.017

[139] Miyagawa, H., Misra, M., Drzal, L.T. and Mohanty, A.K. (2005) Biobased Epoxy/Layered Silicate Nanocomposites: Thermophysical Properties and Fracture Behavior Evaluation. Journal of Polymers and the Environment, 13, 87-96. http://dx.doi.org/10.1007/s10924-005-2940-1

[140] Miyagawa, H., Mohanty, A.K., Burgueno, R., Drzal, L.T. and Misra, M. (2007) Novel Biobased Resins from Blends of Functionalized Soybean Oil and Unsaturated Polyester Resin. Journal of Polymer Science Part B: Polymer Physics, 45, 698-704. http://dx.doi.org/10.1002/polb.21059

[141] Miyagawa, H., Mohanty, A.K., Drzal, L.T. and Misra, M. (2005) Nanocomposites from Biobased Epoxy and SingleWall Carbon Nanotubes: Synthesis, and Mechanical and Thermophysical Properties Evaluation. Nanotechnology, 16, 118-124. http://dx.doi.org/10.1088/0957-4484/16/1/024

[142] Adekunle, K., Akesson, D. and Skrifvars, M. (2010) Biobased Composites Prepared by Compression Molding with a Novel Thermoset Resin from Soybean Oil and a Natural-Fiber Reinforcement. Journal of Applied Polymer Science, 116, 1759-1765.

[143] Mustata, F., Tudorachi, N. and Rosu, D. (2011) Curing and Thermal Behavior of Resin Matrix for Composites Based on Epoxidized Soybean Oil/Diglycidyl Ether of Bisphenol A. Composites Part B: Engineering, 42, 1803-1812. http://dx.doi.org/10.1016/j.compositesb.2011.07.003

[144] Kuriakose, A.P. and Varghese, M. (2003) Use of Rice Bran Oil and Epoxidized Rice Bran Oil in Carbon Black-Filled Natural Rubber-Polychloroprene Blends. Journal of Applied Polymer Science, 90, 4084-4092. http://dx.doi.org/10.1002/app.13146

[145] Fu, C., Zhang, B., Ruan, C., Hua, C., Fua, Y. and Wang, Y. (2010) Improved Hydrolytic Stability Of Poly(DL-Lactide) with Epoxidized Soybean Oil. Polymer Degradation and Stability, 95, 485-490. http://dx.doi.org/10.1016/j.polymdegradstab.2010.01.007

[146] Japon, S., Boogh, L., Leterrier, Y. and Manson, J.A.E. (2000) Reactive Processing of Poly(Ethylene Terephthalate) Modified with Multifunctional Epoxy-Based Additives. Polymer, 41, 5809-5818. http://dx.doi.org/10.1016/S0032-3861(99)00768-5

[147] Ali, F., Young, W., Chang, Y.W., Kang, S.C. and Yoon, J.Y. (2009) Thermal, Mechanical and Theological Properties of Poly(Lactic Acid)/Epoxidized Soybean Oil Blends. Polymer Bulletin, 62, 91-98. http://dx.doi.org/10.1007/s00289-008-1012-9

[148] Zhan, G.Z., Zhao, L., Hu,S., Gan, W.J., Yu, Y.F. and Tang, X.L. (2008) A Novel Biobased Resinepoxidized Soybean Oil Modified Cyanate Ester. Polymer Engineering and Science, 48, 1322-1328. http://dx.doi.org/10.1002/pen.21096

[149] Xu, Y.Q., You, M., Qu, J.P. and Qu, J.P. (2009) Melt Rheology Of Poly(lactic acid) Plasticized by Epoxidized Soybean Oil. Wuhan University Journals Press, 14, 349-354.

[150] Zhang, X., Dieu Do, M., Lusiana, K. and Qiao, G.G. (2010) Wheat Gluten-Based Renewable and Biodegradable Polymer Materials with Enhanced Hydrophobicity by Using Epoxidized Soybean Oil as a Modifier, Carbohydrate Research, 345, 2174-2182. http://dx.doi.org/10.1016/j.carres.2010.07.020

[151] Rana, S., Karak, N., Cho, J.W. and Kim, Y.H. (2008) Enhanced Dispersion of Carbon Nanotubes in Hyperbranched Polyurethane and Properties of Nanocomposites. Nanotechnology, 19, Article ID: 495707. http://dx.doi.org/10.1088/0957-4484/19/49/495707

[152] Cakmakli, B., et al. (2004) Synthesis and Characterization of Polymeric Linseed Oil Grafted Methyl Methacrylate or Styrene. Macromolecular Bioscience, 4, 649-655.

[153] Biswas, A., Adhvaryu. A., Gordon, S.H., Erhan, S.Z. and Willett, J.L. (2005) Synthesis of Diethylamine-Functionalized Soybean Oil. Journal of Agricultural and Food Chemistry, 53, 9485-9490.

http://dx.doi.org/10.1021/jf050731o 
Scientific Research Publishing (SCIRP) is one of the largest Open Access journal publishers. It is currently publishing more than 200 open access, online, peer-reviewed journals covering a wide range of academic disciplines. SCIRP serves the worldwide academic communities and contributes to the progress and application of science with its publication.

Other selected journals from SCIRP are listed as below. Submit your manuscript to us via either submit@scirp.org or Online Submission Portal.
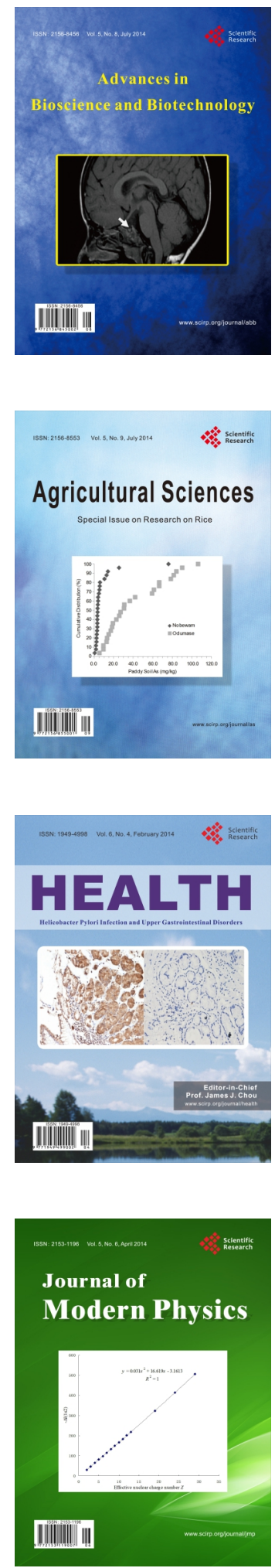
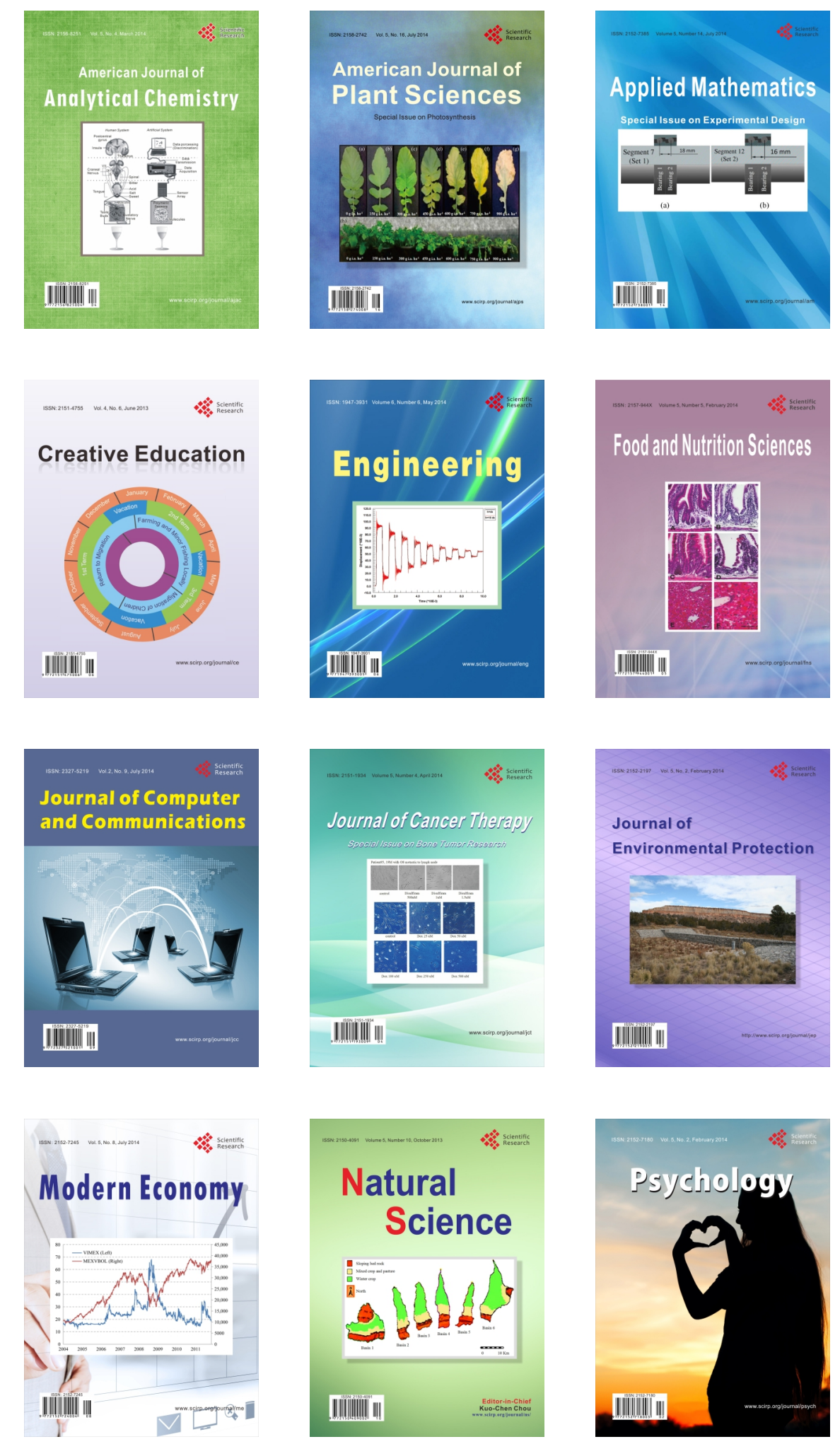